kistvaens, while independent archæologists are, by Government order, forbidden to open any old graves unless they are willing to make over to the Museum all their finds and bear their own expenses. The lapse of time and effects of weather greatly tend to diminish the remains of the old people in the sites they occupied. The action of the plough in many cases, and the trampling of herds of cattle in others, are active elements of destruction of pottery buried near the surface, and even of stone implements. These remarks apply with equal force to the old sites of the early iron age folk, both residential and sepulchral.

Mr. Foote further states in his " Catalogue of the Prehistoric Antiquities" in the Government Museum at Madras, that a full and exhaustive prehistoric survey of the country should be made by a really competent specialist, who shall be a geologist and an osteologist as well as a trained archæologist, and not a mere architectural surveyor. A knowledge of Sanskrit will be of no use in deciding as to the sources whence were derived the many foreign rocks and minerals found in the many old residential sites, which, up to date, have had only their surfaces examined, but which, doubtless, in many cases will yield rich finds to the careful excavator, who must be a man having the power to devote time to his work.

A. C. HADDON.

Cambridge, September 3 .

THE BRITISH ASSOCIATION AT GLASGOW.

$\mathrm{I}$ the previous articles, which appeared in NATURE,

May 23, July 18, and August 22, particulars were given as to the local arrangements for the meeting in Glasgow, and a forecast of the papers to be read at the sectional meetings was published. The president, Principal A. W. Rücker, delivered his presidential address, which we print in this issue, as we went to press yesterday, and the business of the sections commenced this morning. A large number of British leading men of science are present at the meeting, and many well-known men of science are also present from abroad. Among others, the following are attending the meeting :-Prof. L. Kny, Berlin; Prof. George Quincke, Heidelberg ; Prof. G. Mittag-Leffler, Stockholm; Dr. Gustav Cassil, Copenhagen; Prof. A. F. Renard, Ghent; Prof. Gustave Gilson, Louvain; Mr. A. Laurence Rotch, Readville, Mass., U.S.A. ; Prof. R. H. Thurston, Cornell University; Dr. T. P. Lotsy, Arnheim, Holland; Dr. Theodor Beer, Vienna ; Prof. J. J. Mackenzie, Toronto; Prof. E. W. Morley, Cleveland, Ohio ; Prof. Joji Sakurai, Tokyo; His Excellency Don Arturo de Marcoartu, Bilbao ; Prof. J. P. McMurrick, Michigan; Dr. V. Crémieu, Paris ; Prof. Dr. W. Marikwald, Berlin ; Prof. Paul Walden, Riga; Prof. Goebel, Munich ; Dr. C. E. Guillaume, 'Sevres; Dr. Conventz, Danzig; Baron Varilla, Paris ; Mr. Edward Atkinson, Brooklyn; Prof. Anitchkoff, Russia.

The meeting promises to be a successful one, both from the point of view of numbers and that of scientific interest.

Inaugural Address by Prof. Arthur W. Rücke R, M.A., LL.D., D.Sc., Sec.R.S., Presiden'f of the Association.

THE first thought in the minds of all of us to-night is that since we met last year the great Queen, in whose reign nearly all the meetings of the British Association have been held, has passed to her rest.

To Sovereigns most honours and dignities come as of right but for some of them is reserved the supreme honour of an old age softened by the love and benedictions of millions; of a path to the grave, not only magnificent, but watered by the tears both of their nearest and dearest, and of those who, at the most, have only seen them from afar.

This honour Queen Victoria won. All the world knows by what great abilities, by what patient labour, by what infinite tact and kindliness, the late Queen gained both the respect of the rulers of nations and the affection of her own subjects.

Her reign, glorious in many respects, was remarkable, outside these islands, for the growth of the Empire; within and without them, for the drawing nearer of the Crown and the people in mutual trust; while, during her lifetime, the developments of science and of scientific industry have altered the habits and the thoughts of the whole civilised world.

The representatives of science have already expressed in more formal ways their sorrow at the death of Queen Victoria, and the loyalty and confident hope for the future with which they welcome the accession of King Edward. But none the less, I feel sure that at this, the first meeting of the British Association held in his reign, I am only expressing the universal opinion of all our members when I say that no group of the King's subjects trusts more implicitly than we do in the ability, skill, and judg. ment which His Majesty has already shown in the exercise of the powers and duties of his august office; that none sympathise more deeply with the sorrows which two great nations have shared with their Sovereigns; and that none cry with more fervour, "Long live the King !"

But this meeting of the British Association is not only remarkable as being the first in a new reign. It is also the first in a new century. It is held in Glasgow at a time when your International Exhibition has in a special sense attracted the attention of the world to your city, and when the recent celebration of the ninth jubilee of your University has shown how deeply the prosperity of the present is rooted in the past. What wonder then, if I take the Chair to which you have called me with some misgivings? Born and bred in the South, I am to preside over a meeting held in the largest city of Scotland. As your chosen mouthpiece I am to speak to you of science when we stand at the parting of the centuries, and when the achievements of the past and present, and the promise of the future, demand an interpreter with gifts of knowledge and divination to which I cannot pretend. Lastly, I am President of the British Association as a disciple in the home of the master, as a physicist in a city which a physicist has made for ever famous. Whatever the future may have in store for Glasgow, whether your enterprise is still to add wharf to wharf, factory to factory, and street to street, or whether some unforeseen "tide in the affairs of men "is to sweep energy and success elsewhere, fiftythree years in the history of your city will never be forgotten while civilisation lasts.

More than half a century ago, a mere lad was the first to compel the British Association to listen to the teaching of Joule, and to accept the law of the conservation of energy. Now, alike in the most difficult mathematics and in the conception of the most ingenious apparatus, in the daring of his speculations and in the soundness of his engineering, William Thomson, Lord Kelvin, is regarded as a leader by the science and industry of the whole world.

It is the less necessary to dwell at length upon all that he has done, for Lord Kelvin has not been without honour in his own country. Many of us, who meet here to-night, met last' in Glasgow when the University and City had invited representatives of all nations to celebrate the Jubilee of his professorship. For those two or three days learning was surrounded with a pomp seldom to be seen outside a palace. The strange middleage costumes of all the chief Universities of the world were jostling here, the outward signs that those who were themselves distinguished in the study of Nature had gathered to do honour to one of the most distinguished of them all.

Lord Kelvin's achievements were then described in addresses in every tongue, and therefore I will only remind you that we, assembled here to-night, owe him a heavy debt of gratitude ; for the fact that the British Association enters on the twentieth century conscious of a work to do and of the vigour to do it is largely due to his constant presence at its meetings and to the support he has so ungrudgingly given. We have learned to know, not only the work of our great leader, but the man himself; and I count myself happy because in his life-long home, under the walls of the University he served so well, and at a meeting of the Association which his genius has so often illuminated, I am allowed, as your President, to assure him in your name of the admiration, respect, nay, of the affection, in which we all hold him.

I have already mentioned a number of circumstances which make our meeting this year noteworthy; to these $I$ must add that for the first time we have a Section for Education, and the importance of this new departure, due largely to the energy of Prof. Armstrong, is emphasised by the fact that the Chair of that Section will be occupied by the Vice-President of the Committee of Council on Education--Sir John Gorst. I will not attempt to forecast the proceedings of the new Section. Educa- 
tion is passing through a transitional stage. The recent debates in Parliament; the great gifts of Mr. Carnegie; the discussion as to University organisation in the North of England; the reconstitution of the University of London; the increasing importance attached to the application of knowledge both to the investigation of Nature and to the purposes of industry, are all evidence of the growing conviction that without advance in education we cannot retain our position among the nations of the world. If the British Association can provide a platform on which these matters may be discussed in a scientific but practical spirit, free from the misrepresentations of the hustings and the exaggerations of the partisan, it will contribute in no slight measure to the national welfare.

But amid the old and new activities of our meeting the undertone of sadness, which is never absent from such gatherings, will be painfully apparent to many of us at Glasgow. The lifework of Prof. Tait has ended amid the gloom of the war-cloud. A bullet, fired thousands of miles away, struck him to the heart, so that in their deaths the father and the brave son, whom he loved so well, were not long divided. Within the last year, too, America has lost Rowland; Viriamu Jones, who did yeoman's service for education and for science, has succumbed to a long and painful illness; and one who last year at Bradford seconded the proposal that $I$ should be your President at Glasgow, and who would unquestionably have occupied this Chair before long had he been spared to do so, has unexpectedly been called away. A few months ago we had no reason to doubt that George Francis FitzGerald had many years of health and work before him. He had gained in a remarkable way not only the admiration of the scientific world, but the affection of his friends, and we shall miss sadly one whom we all cared for, and who, we hoped, might yet add largely to the achievements which had made him famous.

\section{The Science of the Nineteenth Century.}

Turning from these sad thoughts to the retrospect of the century which has so lately ended, I have found it to be impossible to free myself from the influence of the moment and to avoid, even if it were desirable to avoid, the inclination to look backward from the standpoint of to-day.

Two years ago Sir Michael Foster dealt with the work of the century as a whole. Last year Sir William Turner discussed in greater detail the growth of a single branch of science. A third and humbler task remains, viz., to fix our attention on some of the hypotheses and assumptions on which the fabric of modern theoretical science has been built, and to inquire whether the foundations have been so "well and truly" laid that they may be trusted to sustain the mighty superstructure which is being raised upon them.

The moment is opportune. The three chief conceptions which for many years have dominated physical as distinct from biological science have been the theories of the existence of atoms, of the mechanical nature of heat, and of the existence of the ether.

Dalton's atomic theory was first given to the world by a Glasgow professor-Thomas Thomson-in the year I807, Dalton having communicated it to him in I804. Rumford's and Davy's experiments on the nature of heat were published in I798 and I799 respectively; and the celebrated Bakerian Lecture, in which Thomas Young established the undulatory theory by explaining the interference of light, appeared in the Philosophical Transactions in I80I. The keynotes of the physical science of the nineteenth century were thus struck, as the century began, by four of our fellow-countrymen, one of whom-Sir Benjamin Thompson, Count Rumford-preferred exile from the land of his birth to the loss of his birthright as a British citizen.

\section{Doubts as to Scientific Theories.}

It is well known that of late doubts have arisen as to whether the atomic theory, with which the mechanical theory of heat is closely bound up, and the theory of the existence of an ether have not served their purpose, and whether the time has not come to reconsider them.

The facts that Prof. Poincaré, addressing a congress of physicists in Paris, and Prof. Poynting, addressing the Physical Section of the Association, have recently discussed the true meaning of our scientific methods of interpretation; that Dr. James Ward has lately delivered an attack of great power on many positions which eminent scientific men have occupied; and that the approaching end of the nineteenth century led Prof. Haeckel to define in a more popular manner his own very definite views as to the solution of the "Riddle of the Universe," are perhaps a sufficient justification of an attempt to lay before you the difficulties which surround some of these questions.

To keep the discussion within reasonable limits, I shall illustrate the principles under review by means of the atomic theory, with comparatively little reference to the ether, and we may also at first confine our attention to inanimate objects.

\section{The Construction of a Model of Nature.}

A natural philosopher, to use the old phrase, even if only possessed of the most superficial knowledge, would attempt to bring some order into the results of his observation of Nature by grouping together statements with regard to phenomena which are obviously related. The aim of modern science goes far beyond this. It not only shows that many phenomena are related which at first sight have little or nothing in common, but, in so doing, also attempts to explain the relationship.

Without spending time on a discussion of the meaning of the word "explanation," it is sufficient to say that our efforts to establish relationships between phenomena often take the form of attempting to prove that, if a limited number of assumptions are granted as to the constitution of matter, or as to the existence of quasi-material entities, such as caloric, electricity, and the ether, a wide range of observed facts falls into order as a necessary consequence of the assumptions. The question at issue is whether the hypotheses which are at the base of the scientific theories now most generally accepted are to be regarded as accurate descriptions of the constitution of the universe around us, or merely as convenient fictions.

Convenient fictions be it observed, for even if they are fictions they are not useless. From the practical point of view it is a matter of secondary importance whether our theories and assumptions are correct, if only they guide us to results which are in accord with facts. The whole fabric of scientific theory may be regarded merely as a gigantic " aid to memory"; as a means for producing apparent order out of disorder by codifying the observed facts and laws in accordance with an artificial system, and thus arranging our knowledge under a comparatively smal number of heads. The simplification introduced by a scheme which, however imperfect it may be, enables us to argue from a few first principles, makes theories of practical use. By means of them we can foresee the results of combinations of causes which would otherwise elude us. We can predict future events, and can even attempt to argue back from the present to the unknown past.

But it is possible that these advantages might be attained by means of axioms, assumptions, and theories based on very false ideas. A person who thought that a river was reaily a streak of blue paint might learn as much about its direction from a map as one who knew it as it is. It is thus conceivable that we might be able, not indeed to construct, but to imagine, something more than a mere map or diagram, something which might even be called a working model of inanimate objects, which was nevertheless very unlike the realities of Nature. Of course, the agreement between the action of the model and the behaviour of the things it was designed to represent would probably be imperfect, unless the one were a facsimile of the other; but it is conceivable that the correlation of natural phenomena could be imitated, with a large measure of success, by means of an imaginary machine, which shared with a map or diagram the characteristic that it was in many ways unlike the things it represented, but might be compared to a model in that the behaviour of the things represented could be predicted from that of the corresponding parts of the machine.

We might even go a step further. If the laws of the working of the model could be expressed by abstractions, as, for example, by mathematical formulæ, then, when the formulæ were obtained, the model might be discarded, as probably unlike that which it was made to imitate, as a mere aid in the construction of equations, to be thrown aside when the perfect structure of mathematical symbols was erected.

If this course were adopted, we should have given up the attempt to know more of the nature of the objects which surround us than can be gained by direct observation, but might nevertheless have learned how these objects would behave under given circumstances.

We should have abandoned the hope of a physical explanation 
of the properties of inanimate Nature, but should have secured a mathematical description of her operations.

There is no doubt that this is the easiest path to follow. Criti. cism is avoided if we admit from the first that we cannot go below the surface; cannot know anything about the constitution of material bodies; but must be content with formulating a description of their behaviour by means of laws of Nature expressed by equations.

But if this is to be the end of the study of Nature, it is evident that the construction of the model is not an essential part of the process. The model is used merely as an aid to thinking; and if the relations of phenomena can be investigated without it, so much the better. The highest form of theory-it may be saidthe widest kind of generalisation, is that which has given up the attempt to form clear mental pictures of the constitution of matter, which expresses the facts and the laws by language and symbols which lead to results that are true, whatever be our view as to the real nature of the objects with which we deal. From this point of view the atomic theory becomes not so much false as unnecessary; it may be regarded as an attempt to give an unnatural precision to ideas which are and must be vague.

Thus, when Rumford found that the mere friction of metals produced heat in unlimited quantity, and argued that heat was therefore a mode of motion, he formed a clear mental picture of what he believed to be occurring. But his experiments may be quoted as proving only that energy can be supplied to a body in indefinite quantity, and when supplied by doing work against friction it appears in the form of heat.

By using this phraseology we exchange a vivid conception of moving atoms for a colourless statement as to heat energy, the real nature of which we do not attempt to define; and methods which thus evade the problem of the nature of the things which the symbols in our equations represent have been prosecuted with striking success, at all events within the range of a limited class of phenomena. A great school of chemists, building upon the thermodynamics of Willard Gibbs and the intuition of Van t'Hoff, have shown with wonderful skill that, if a sufficient number of the data of experiment are assumed, it is possible, by the aid of thermodynamics, to trace the form of the relations between many physical and chemical phenomena without the help of the atomic theory.

But this method deals only with matter as our coarse senses know it; it does not pretend to penetrate beneath the surface.

It is therefore with the greatest respect for its authors, and with a full recognition of the enormous power of the weapons employed, that I venture to assert that the exposition of such a system of tactics cannot be regarded as the last word of science in the struggle for the truth.

Whether we grapple with them, or whether we shirk them; however much or however little we can accomplish without answering them, the questions still force themselves upon us : Is matter what it seems to be ? Is interplanetary space full or empty? Can we argue back from the direct impressions of our senses to things which we cannot directly perceive; from the phenomena displayed by matter to the constitution of matter itself?

It is these questions which we are discussing to-night, and we may therefore, as far as the present address is concerned, put aside, once for all, methods of scientific exposition in which an attempt to form a mental picture of the constitution of matter is practically abandoned, and devote ourselves to the inquiries whether the effort to form such a picture is legitimate, and whether we have any reason to believe that the sketch which science has already drawn is to some extent a copy, and not a mere diagram, of the truth.

\section{Successive Steps in the Analysis of Matter.}

In dealing, then, with the question of the constitution of matter and the possibility of representing it accurately, we may grant at once that the ultimate nature of things is, and must remain, unknown; but it does not follow that immediately below the complexities of the superficial phenomena which affect our senses there may not be a simpler machinery of the existence of which we can obtain evidence, indirect indeed, but conclusive.

The fact that the apparent unity which we call the atmosphere can be resolved into a number of different gases is admitted; though the ultimate nature of oxygen, nitrogen, argon, carbonic acid, and water vapour is as unintelligible as that of air as a

$$
\text { NO. I } \left.66_{3} \text {, VOL. } 64\right]
$$

whole, so that the analysis of air may be said to have substituted many incomprehensibles for one.

Nobody, however, looks at the question from this point of view. It is recognised that an investigation into the proximate constitution of things may be useful and successful, even if their ultimate nature is beyond our ken.

Nor need the analysis stop at the first step. Water vapour and carbonic acid, themselves constituents of the atmosphere, are in turn resolved into their elements, hydrogen, oxygen, and carbon, which, without a formal discussion of the criteria of reality, we may safely say are as real as air itself.

Now, at what point must this analysis stop if we are to avoid crossing the boundary between fact and fiction? Is there any fundamental difference between resolving air into a mixture of gases and resolving an elementary gas into a mixture of atoms and ether?

There are those who cry halt ! at the point at which we divide a gas into molecules, and their first ubjection seems to be that molecules and atoms cannot be directly perceived, cannot be seen or handled, and are mere conceptions, which have their uses, but cannot be regarded as realities.

It is easiest to reply to this objection by an illustration.

The rings of Saturn appear to be continuous masses separated by circular rifts. This is the phenomenon which is observed through a telescope. By no known means can we ever approach or handle the rings; yet everybody who understands the evidence now believes that they are not what they appear to be, but consist of minute moonlets, closely packed indeed, but separate the one from the other.

In the first place, Maxwell proved mathematically that if a Saturnian ring were a continuous solid or fluid mass it would be unstable and would necessarily break into fragments. In the next place, if it were possible for the ring to revolve like a solid body, the inmost parts would move slowest, while a satellite moves faster the nearer it is to a planet. Now, spectroscopic observation, based on the beautiful method of Sir W. Huggins, shows not only that the inner portions of the ring move the more rapidly, but that the actual velocities of the outer and inner edges are in close accord with the theoretical velocities of satellites at like distances from the planet.

This and a hundred similar cases prove that it is possible to obtain convincing evidence of the constitution of bodies between whose separate parts we cannot directly distinguish, and I take it that a physicist who believes in the reality of atoms thinks that he has as good reason for dividing an apparently continuous gas into molecules as he has for dividing the apparently continuous Saturnian rings into satellites. If he is wrong, it is not the fact that molecules and satellites alike cannot be handled and can. not be seen as individuals, that constitutes the difference between the two cases.

It may, however, be urged that atoms and the ether are alleged to have properties different from those of matter in bulk, of which alone our senses take direct cognisance, and that therefore it is impossible to prove their existence by evidence of the same cogency as that which may prove the existence of a newly discovered variety of matter or of a portion of matter too small or too distant to be seen.

This point is so important that it requires full discussion, but in dealing with it, it is necessary to distinguish carefully between the validity of the arguments which support the earlier and more fundamental propositions of the theory; and the evidence brought forward to justify mere speculative applications of its doctrines which might be abandoned without discarding the theory itself. The proof of the theory must be carried out step by step.

The first step is concerned wholly with some of the most general properties of matter, and consists in the proof that those properties are either absolutely unintelligible, or that, in the case of matter of all kinds, we are subject to an illusion similar to that the results of which we admit in the case of Saturn's rings, clouds, smoke, and a number of similar instances. The believer in the atomic theory asserts that matter exists in a particular state; that it consists of parts which are separate and distinct the one from the other, and as such are capable of independent movements.

Up to this point no question arises as to whether the separate parts are, like grains of sand, mere fragments of matter; or whether, though they are the bricks of which matter is built, they have, as individuals, properties different from those of masses of matter large enough to be directly perceived. If they 
are mere fragments of ordinary matter, they cannot be used as aids in explaining those qualities of matter which they themselves share.

We cannot explain things by the things themselves. If it be true that the properties of matter are the product of an underlying machinery, that machinery cannot itself have the properties which it produces, and must, to that extent at all events, differ from matter in bulk as it is directly presented to the senses.

If, however, we can succeed in showing that if the separate parts have a limited number of properties (different, it may be, from those of matter in bulk), the many and complicated properties of matter can, to a considerable extent, be explained as consequences of the constitution of these separate parts; we shall have succeeded in establishing, with regard to quantitative properties, a simplification similar to that which the chemist has established with regard to varieties of matter. The many will have been reduced to the few.

The proofs of the physical reality of the entities discovered by means of the two analyses must necessarily be different. The chemist can actually produce the elementary constituents into which he has resolved a compound mass. No physicist or chemist can produce a single atom separated from all its fellows, and show that it possesses the elementary qualities he assigns to it. The cogency of the evidence for any suggested constitution of atoms must vary with the number of facts which the hypothesis that they possess that constitution explains.

Let us take, then, two steps in their proper order, and inquire, first, whether there is valid ground for believing that all matte is made up of discrete parts; and secondly, whether we can have any knowledge of the constitution or properties which those parts possess.

\section{The Coarse-grainediness of Matter.}

Matter in bulk appears to be continuous. Such substances as water or air appear to the ordinary observer to be perfectly uniform in all their properties and qualities, in all their parts.

The hasty conclusion that these bodies are really uniform is, nevertheless, unthinkable.

In the first place, the phenomena of diffusion afford conclusive proof that matter when apparently quiescent is in fact in a state of internal commotion. I need not recapitulate the familiar evidence to prove that gases and many liquids when placed in communication interpenetrate or diffuse into each other; or that air, in contact with a surface of water, gradually becomes laden with water vapour, while the atmospheric gases in turn mingle with the water. Such phenomena are not exhibited by liquids and gases alone, or by solids at high temperatures only. Sir W. Roberts-Austen has placed pieces of gold and lead in contact at a temperature of $18^{\circ} \mathrm{C}$. After four years the gold had travelled into the lead to such an extent that not only were the two metals united, but, on analysis, appreciable quantities of the gold were detected even at a distance of more than 5 millimetres from the common surface, while within a distance of three-quarters of a millimetre from the surface gold had penetrated into the lead to the extent of I oz. 6 dwts. per ton, an amount which could have been profitably extracted.

Whether it is or is not possible to devise any other intelligible account of the cause of such phenomena, it is certain that a simple and adequate explanation is found in the hypothesis that matter consists of discrete parts in a state of motion, which can penetrate into the spaces between the corresponding parts of surrounding bodies.

The hypothesis thus framed is also the only one which affords a rational explanation of other simple and well-known facts. If matter is regarded as a continuous medium, the phenomena of expansion are unintelligible. There is, apparently, no limit to the expansion of matter, or, to fix our attention on one kind of matter, let us say to the expansion of a gas; but it is inconceivable that a continuous material which fills or is present in every part of a given space could also be present in every part of a space a million times as great. Such a statement might be made of a mathematical abstraction; it cannot be true of any real substance or thing. If, however, matter consists of discrete particles, separated from each other either by empty space or by something different from themselves, we can at once understand that expansion and contraction may be nothing more than the mutual separation or approach of these particles.

Again, no clear mental picture can be formed of the phenomena of heat unless we suppose that heat is a mode of motion. In the words of Rumford, it is "extremely difficult, if not NO. I 663 , VOL. 64$]$ quite impossible, to form any distinct idea of anything capable of being excited and communicated in the manner the heat was excited and communicated in [his] experiment [on friction] except it be motion" (Phil. Trans., I798, p. 99). And if hea be motion there can be no doubt that it is the fundamental particles of matter which are moving. For the motion is not visible, is not motion of the body as a whole, while diffusion, which is a movement of matter, goes on more quickly as the temperature rises, thereby proving that the internal motions have become more rapid, which is exactly the result which would follow if these were the movements which constitute sensible heat.

Combining, then, the phenomena of diffusion, expansion, and heat, it is not too much to say that no hypotheses which make them intelligible have ever been framed other than those which are at the basis of the atomic theory.

Many other considerations also point to the same conclusion. Many years ago Lord Kelvin gave independent arguments, based on the properties of gases, on the constitution of the surfaces of liquids, and on the electric properties of metals, all of which indicate that matter is, to use his own phrase, coarsegrained-that it is not identical in constitution throughout, but that adjacent minute parts are distinguishable from each other by being either of different natures or in different states.

And here it is necessary to insist that all these fundamental proofs are independent of the nature of the particles or granules into which matter must be divided.

The particles, for instance, need not be different in kind from the medium which surrounds and separates them. It would suffice if they were what may be called singular parts of the medium itself, differing from the rest only in some peculiar state of internal motion or of distortion, or by being in some other way earmarked as distinct individuals. The view that the constitution of matter is atomic may and does receive support from theories in which definite assumptions are made as to the constitution of the atoms; but when, as is often the case, these assumptions introduce new and more recondite difficulties, it must be remembered that the fundamental hypothesis-that matter consists of discrete parts, capable of independent motions-is forced upon us by facts and arguments which are altogether independent of what the nature and properties of these separate parts may be.

As a matter of history, the two theories, which are not by any means mutually exclusive, that atoms are particles which can be treated as distinct in kind from the medium which surrounds them, and that they are parts of that medium existing in a special state, have both played a large part in the theoreti cal development of the atomic hypothesis. The atoms of Waterston, Clausius, and Maxwell were particles. The vortexatoms of Lord Kelvin, and the strain-atoms (if I may call them so) suggested by Mr. Larmor, are states of a primary medium which constitutes a physical connection between them, and through which their mutual actions arise and are transmitted.

\section{Properties of the Basis of Matter.}

It is easy to show that, whichever alternative be adopted, we are dealing with something, whether we consider it under the guise of separate particles or of differentiated portions of the medium, which has properties different from those of matter in bulk.

For if the basis of matter had the same constitution as matter, the irregular heat movements could hardly be maintained either against the viscosity of the medium or the frittering away of energy of motion which would occur during the collisions between the particles. Thus, even in the case in which a hot body is prevented from losing heat to surrounding objects, its sensible heat should spontaneously decay by a process of selfcooling. No such phenomenon is known, and though on this, as on all other points, the limits of our knowledge are fixed by the uncertainty of experiment, we are compelled to admit that, to all appearance, the fundamental medium, if it exists, is unlike a material medium, in that it is non-viscous ; and that the particles, if they exist, are so constituted that energy is not frittered away when they collide. In either case, we are dealing with something different from matter itself in the sense that, though it is the basis of matter, it is not identical in all its properties with matter.

The idea therefore that entities exist possessing properties different from those of matter in bulk is not introduced at the end of a long and recondite investigation to explain facts with 
which none but experts are acquainted. It is forced upon us at the very threshold of our study of Nature. Either the properties of matter in bulk cannot be referred to any simpler structure, or that simpler strncture must have properties different from those of matter in bulk as we directly knew it-properties which can only be inferred from the results which they produce.

No a priori argument against the possibility of our discovering the existence of quasi-material substances, which are nevertheless different from matter, can prove the negative proposition that such substances cannot exist. It is not a self-evident truth that no substance other than ordinary matter can have an existence as real as that of matter itself. It is not axiomatic that matter cannot be composed of parts whose properties are different from those of the whole. To assert that even if such substances and such parts exist no evidence however cogent could convince us of their existence is to beg the whole question at issue ; to decide the cause before it has been heard.

We must therefore adhere to the standpoint adopted by most scientific men, viz., that the question of the existence of ultraphysical entities, such as atoms and the ether, is to be settled by the evidence, and must not be ruled out as inadmissible on $a$ priori grounds.

On the other hand, it is impossible to deny that, if the mere entry on the search for the concealed causes of physical phenomena is not a trespass on ground we have no right to explore, it is at all events the beginning of a dangerous journey.

The wraiths of phlogiston, caloric, luminiferous corpuscles, and a crowd of other phantoms haunt the investigator, and as the grim host vanishes into nothingness he cannot but wonder if his own conceptions of atoms and of the ether

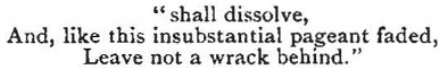

But though science, like Bunyan's hero, has sometimes had to pass through the "Valley of Humiliation," the spectres which meet it there are not really dangerous if they are boldly faced. The facts that mistakes have been made, that theories have been propounded, and for a time accepted, which late investigations have disproved, do not necessarily discredit the method adopted. In scientific theories, as in the world around us, there is a survival of the fittest, and Dr. James Ward's un sympathetic account of the blunders of those whose work, after all, has shed glory on the nineteenth century, might mutati mutandis stand for a description of the history of the advance of civilisation. "The story of the progress so far," he tells us, " is briefly this: Divergence between theory and fact one part of the way, the wreckage of abandoned fictions for the rest, and an un attainable goal of phenomenal nihilism and ultra-physical mechanism beyond" ("Naturalism and Agnosticism," vol. i. p. I 53).

"The path of progress," says Prof. Karl Pearson, "is strewn with the wreck of nations. Traces are everywhere to be seen of the hecatombs of inferior races, and of victims who found not the narrow way to the greater perfection. Yet these dead peoples are, in very truth, the stepping-stones on which mankind has arisen to the higher intellectual and deeper emotional life of to-day " ("National Life from the Standpoint of Science," p. 62).

It is only necessary to add that the progress of society is directed towards an unattainable goal of universal contentment, to make the parallel complete.

And so, in the one case as in the other, we may leave " the dead to bury their dead." The question before us is not whether we too may not be trusting to false ideas, erroneous experi ments, evanescent theories. No doubt we are; but, without making an insolent claim to be better than our fathers, we may fairly contend that, amid much that is uncertain and temporary, some of the fundamental conceptions, some of the root-ideas of science, are so grounded on reason and fact that we cannot but regard them as an aspect of the very truth.

Enough has, perhaps, now been said on this point for my immediate purpose. The argument as to the constitution of matter could be developed further in the manner I have hitherto adopted, viz. by series of propositions, the proof of each of which is based upon a few crucial phenomena. In particular, if matter is divided into moving granules or particles, the phenomenon of cohesion proves that there must be mutual actions between them analogous to those which take place between large masses of matter, and which we ascribe to force, thereby indicating the regular, unvarying operation of active machinery which we have not yet the means of adequately understanding. For the moment, I do not wish to extend the line of reasoning that has been followed. My main object is to show that the notion of the existence of ultra-physical entities and the leading outlines of the atomic theory are forced upon us at the beginning of our study of Nature, not only by a priori considerations, but in the attempt to comprehend the results of even the simplest observa. tion. These outlines cannot be effaced by the difficulties which undoubtedly arise in filling up the picture. The cogency of the proof that matter is coarse-grained is in no way affected by the fact that we may have grave doubts as to the nature of the granules. Nay, it is of the first importance to recognise that, though the fundamental assumptions of the atomic theory receive overwhelming support from a number of more detailed arguments, they are themselves almost of the nature of axioms, in that the simplest phenomena are unintelligible if they are abandoned.

\section{The Range of the Atomic Theory.}

It would be most unfair, however, to the atomic theory to represent it as depending on one line of reasoning only, or to treat its evidence as bounded by the very general propositions $I$ have discussed.

It is true that as the range of the theory is extended the fundamental conception that matter is granular must be expanded and filled in by supplementary hypotheses as to the constitution of the granules. It may also be admitted that no complete or wholly satisfactory description of that constitution can as yet be given; that perfection has not yet been attained here or in any other branch of science; but the number of facts which can be accounted for by the theory is very large compared with the number of additional hypotheses which are introduced; and the cumulative weight of the additional evidence obtained by the study of details is such as to add greatly to the strength of the conviction that, in its leading outlines, the theory is true.

It was originally suggested by the facts of chemistry, and though, as we have seen, a school of chemists now thrusts it into the background, it is none the less true, in the words of Dr. Thorpe, that "every great advance in chemical knowledge during the last ninety years finds its interpretation in [Dalton's] theory" ("Essays on Historical Chemistry," 1894, p. 368).

The principal mechanical and thermal properties of gases have been explained, and in large part discovered, by the aid of the atomic theory; and, though there are outstanding difficulties, they are, for the most part, related to the nature of the atoms and molecules, and do not affect the question as to whether they exist.

The fact that different kinds of light all travel at the same speed in interplanetary space, while they move at different rates in matter, is explained if matter is coarse-grained. But to attempt to sum up all this evidence would be to recite a textbook on physics. It must suffice to say that it is enormous in extent and varied in character, and that the atomic theory imparts a unity to all the physical sciences which has been attained in no other way.

I must, however, give a couple of instances of the wonderful success which has been achieved in the explanation of physical phenomena by the theory we are considering, and I select them because they are in harmony with the line of argument I have been pursuing.

When a piece of iron is magnetised, its behaviour is different according as the magnetic force applied to it is weak, moderate, or strong. When a certain limit is passed, the iron behaves as a non-magnetic substance to all further additions of magnetic force. With strong forces it does and with very weak forces it does not remain magnetised when the force ceases to act. Prof. Ewing has imitated all the minute details of these complicated properties by an arrangement of small isolated compass needles to represent the molecules. It may fairly be said that as far as this particular set of phenomena is concerned a most instructive working model based on the molecular theory has not only been imagined but constructed

The next illustration is no less striking. We may liken a crowd of molecules to a fog; but while the fog is admitted by everybody to be made up of separate globules of water, the critics of scientific method are sometimes apt to regard the molecules as mere fictions of the imagination. If, however, we could throw the molecules of a highly rarefied gas into such a state that vapour condensed on them, so that each became the centre of a water-drop, till the host of invisible molecules was, as it were, magnified by accretion into a visible mist, surely no 
stronger proof of their reality could be desired. Yet there is every reason to believe that something very like this has been accomplished by Mr. C. T. R. Wilson and Prof. J. J. Thomson.

It is known that it is comparatively difficult to produce a fog in damp air if the mixture consists of air and water-vapour alone. The presence of particles of very fine dust facilitates the process. It is evident that the vapour condenses on the dust particles, and that a nucleus of some kind is necessary on which each drop may form. But electrified particles also act as nuclei ; for if a highly charged body from which electricity is escaping be placed near a steam jet, the steam condenses; and a cloud is also formed in dust-free air more easily than would otherwise be the case if electricity is discharged into it.

Again, according to accepted theory, when a current of electricity flows through a gas, some of the atoms are divided into parts which carry positive and negative charges as they move in opposite directions, and unless this breaking-up occurs a gas does not conduct electricity. But a gas can be made a conductor merely by allowing the Röntgen rays or the radiation given off by uranium to fall upon it. A careful study of the facts shows that it is probable that some of the atoms have been broken up by the radiation, and that their oppositely electrified parts are scattered among their unaltered fellows. Such a gas is said to be ionised.

Thus by these two distinct lines of argument we come to the conclusions :-Ist, that the presence of electrified particles promotes the formation of mist, and 2nd, that in an ionised gas such electrified particles are provided by the breaking-up of atoms.

The two conclusions will mutually support each other if it can be shown that a mist is easily formed in ionised air. This was tested by Mr. Wilson, who showed that in such air mist is formed as though nuclei were present, and thus in the cloud we have visible evidence of the presence of the divided atoms. If then, we cannot handle the individual molecules, we have at least some reason to believe that a method is known of seizing individuals, or parts of individuals, which are in a special state, and of wrapping other matter round them till each one is the centre of a discrete particle of a visible fog.

I have purposely chosen this illustration, because the explanation is based on a theory - that of ionisation-which is a present subjected to hostile criticism. It assumes that an electrical current is nothing more than the movement of charges of electricity. But magnets placed near to an electric current tend to set themselves at right angles to its direction; a fact on which the construction of telegraphic instruments is based. Hence if the theory be true, a similar effect ought to be produced by a moving charge of electricity. This experiment was tried many years ago in the laboratory of Helmholtz by Rowland, who caused a charged disc to spin rapidly near a magnet. The result was in accord with the theory; the magnet moved as though acted upon by an electric current. Of late, however M. Crémieu has investigated the matter afresh, and has obtained results which, according to his interpretation, were inconsistent with that of Rowland.

M. Crémieu's results are already the subject of controversy, and are, I believe, likely to be discussed in the Section of Physics. This is not the occasion to enter upon a critical dis cussion of the question at issue, and I refer to it only to point out that though, if M. Crémieu's result were upheld, our views as to electricity would have to be modified, the foundations of the atomic theory would not be shaken.

It is, however, from the theory of ions that the most farreaching speculations of science have recently received unexpected support. The dream that matter of all kinds will some day be proved to be fundamentally the same has survived many shocks. The opinion is consistent with the great generalisation that the properties of elements are a periodic function of their atomic weights. Sir Norman Lockyer has long been a prominent exponent of the view that the spectra of the stars indicate the reduction of our so-called elements to simpler forms, and now Prof. J. J. Thomson believes that we can break off from an atom a part, the mass of which is not more than one-thousandth of the whole, and that these corpuscles, as he has named them, are the carriers of the negative charge in an electric current. If atoms are thus complex, not only is the a priori probability increased that the different structures which we call elements may all be built of similar bricks, but the discovery by Lenard

1 See.Phil. Mag., July rgor, p. 144; and Johns Hopkins University Circulars, xx. No: 152, May-June 1901, p. 78 . No. [663, VOL. 64$]$ that the ease with which the corpuscles penetrate different bodies depends only on the density of the obstacles, and not on their chemical constitution, is held by Prof. Thomson to be " a strong confirmation of the view that the atoms of the elementary substances are made up of simpler parts, all of which are alike." 1 On the present occasion, however, we are occupied rather with the foundations than with these ultimate ramifications of the atomic theory; and having shown how wide its range is, I must, to a certain extent, retrace my steps and return to the main line of my argument.

\section{The Properties of Atoms and Molecules.}

For if it be granted that the evidence that matter is coarsegrained and is formed of separate atoms and molecules is too strong to be resisted, it may still be contended that we can know little or nothing of the sizes and properties of the molecules.

It must be admitted that, though the fundamental postulates are always the same, different aspects of the theory, which have not in all cases been successfully combined, have to be developed when it is applied to different problems; but in spite of thi there is little doubt that we have some fairly accurate knowledge of molecular motions and magnitudes.

If a liquid is stretched into a very thin film, such as a soapbubble, we should expect indications of a change in its properties when the thickness of the film is not a very large multiple of the average distance between two neighbouring molecules. In 1890 Sohncke (Wied. Ann., I890, xl. pp. 345-355) detected evidence of such a change in films of the average thickness of I06 millionths of a millimetre $(\mu \mu)$, and quite recently Rudolph Weber found it in an oil-film when the thickness was $115 \mu \mu$ (Annalen der Physik, 190I, iv. pp. 706-721).

Taking the mean of these numbers and combining the results of different variants of the theory, we may conclude that a film should become unstable and tend to rupture spontaneously somewhere between the thicknesses of 1 IO and $55 \mu \mu$, and Prof. Reinold and I found by experiment that this instability is actually exhibited between the thicknesses of 96 and $45 \mu \mu$ (Phil. Trans., I893, I84, pp. 505-529). There can therefore be little doubt that the first approach to molecular magnitudes is signalled when the thickness of a film is somewhat less than IOO $\mu \mu$, or 4 millionths of an incb.

Thirteen years ago I had the honour of laying before the Chemical Society a résumé of what was then known on these subjects (Chem. Soc. Trans., liii., March 1888, pp. 222-262), and I must refer to that lecture or to the most recent edition of O. E. Meyer's work on the kinetic theory of gases ("Kinetic Theory of Gases," O. E. Meyer, I899; translated by R. E. Baynes) for the evidence that various independent lines of argument enable us to estimate quantities very much less than 4 millionths of an inch, which is perhaps from 500 to 1000 times greater than the magnitude which, in the present state of our knowledge, we can best describe as the diameter of a molecule.

Confining our attention, however, to the larger quantities, I will give one example to show how strong is the cumulative force of the evidence as to our knowledge of the magnitudes of molecular quantities.

We have every reason to believe that though the molecules in a gas frequently collide with each other, yet in the case of the more perfect gases the time occupied in collisions is small compared with that in which each molecule travels undisturbed by its fellows. The average distance travelled between two successive encounters is called the mean free path, and, for the reason just given, the question of the magnitude of this distance can be attacked without any precise knowledge of what a mole. cule is, or of what happens during an encounter.

Thus the mean free path can be determined, by the aid of the theory, either from the viscosity of the gas or from the thermal conductivity. Using figures given in the latest work on the subject (Meyer's "Kinetic Theory of Gases"; see above), and dealing with one gas only, as a fair sample of the rest, the lengths of the mean free path of hydrogen as determined by these two independent methods differ only by about 3 per cent. Further, the mean of the values which I gave in the lecture already referred to differed only by about 6 per cent. from the best modern result, so that no great change has been introduced during the last thirteen years.

1 For the most recent account of this subject see an article on "Bodies Smaller than Atoms," by Prof. J. J. Thomson in the Popular Science Monthly (The Science Press), August igor. 
It may, however, be argued that these concordant values are all obtained by means of the same theory, and that a common error may affect them all. In particular, some critics have of late been inclined to discredit the atomic theory by pointing out that the strong statements which have sometimes been made as to the equality, among themselves, of atoms or molecules of the same kind may not be justified, as the equality may be that of averages only, and be consistent with a considerable variation in the sizes of individuals.

Allowing this argument more weight than it perhaps deserves, it is easy to show that it cannot affect seriously our knowledge of the length of the mean free path.

Prof. George Darwin (Piil. Trans., 180) has handled the problem of a mixture of unequal spherical bodies in the particular case in which the sizes are distributed according to the law of errors, which would involve far greater inequalities than can occur among atoms. Without discussing the precise details of his problem, it is sufficient to say that in the case considered by him the length of the mean free path is 7/I I of what it would be if the particles were equal. Hence, were the inequalities of atoms as great as in this extreme case, the reduction of the mean free path in hydrogen could only be from 185 to $119 \mu u$; but they must be far less, and therefore the error, if any, due to this cause could not approach this amount. It is probably inappreciable.

Such examples might be multiplied, but the one I have selected is perhaps sufficient to illustrate my point, viz., that considerable and fairly accurate knowledge can be obtained as to molecular quantities by the aid of theories the details of which are provisional, and are admittedly capable of improve. ment.

\section{Is the Model Unique?}

But the argument that a correct result may sometimes be obtained by reasoning on imperfect hypotheses raises the question as to whether another danger may not be imminent. To be satisfactory, our model of Nature must be unique, and it must be impossible to imagine any other which agrees equally well with the facts of experiment. If a large number of hypotheses could be framed with equal claims to validity, that fact would alone raise grave doubts as to whether it were possible to distinguish between the true and the false. Thus Prof. Poincaré has shown that an infinite number of dynamical explanations can be found for any phenomenon which satisfies certain conditions. But though this consideration warns us against the too ready accept ance of explanations of isolated phenomena, it has no weight against a theory which embraces so vast a number of facts as those included by the atomic theory. It does not follow that, because a number of solutions are all formally dynamical, they are therefore all equally admissible. The pressure of a gas may be explained as the result of a shower of blows delivered by molecules, or by a repulsion between the various parts of a con. tinuous medium. Both solutions are expressed in dynamical language ; but one is, and the other is not, compatible with the observed phenomena of expansion. The atomic theory must hold the field until another can be found which is not inferior as an explanation of the fundamental difficulties as to the constitution of matter, and is, at the same time, not less comprehensive.

On the whole, then, the question as to whether we are attempting to solve a problem which has an infinite number of solutions may be put aside until one solution has been found which is satisfactory in all its details. We are in a sufficient difficulty about that to make the rivalry of a second of the same type very improbable.

\section{The Phenomena of Life.}

But it may be asked-nay, it has been asked-may not the type of our theories be radically changed? If this question does not merely imply a certain distrust in our own powers of reasoning, it should be supported by some indication of the kind of change which is conceivable.

Perhaps the chief objection which can be brought against physical theories is that they deal only with the inanimate side of Nature, and largely ignore the phenomena of life. It is therefore in this direction, if in any, that a change of type may be expected. I do not propose to enter at length upon so diffi cult a question, but, however we may explain or explain away the characteristics of life, the argument for the truth of the at omic theory would only be affected if it could be shown that living matter does not possess the thermal and mechanical prope rties, to explain which the atomic theory has been framed. This is so notoriously not the case that there is the gravest doubt whether life can in any way interfere with the action within the organism of the laws of matter in bulk belonging to the domain of mechanics, physics, and chemistry.

Probably the most cautious opinion that could now be expressed on this question is that, in spite of some outstanding difficulties which have recently given rise to what is called Neovitalism, there is no conclusive evidence that living matter can suspend or modify any of the natural laws which would affect it if it were to cease to live. It is possible that though subject to these laws the organism while living may be able to employ, or even to direct, their action within itself for its own benefit, just as it unquestionably does make use of the processes of external nature for its own purposes; but if this be so, the seat of the controlling influence is so withdrawn from view that, on the one hand, its very existence may be denied, while, on the other hand, Prof. Haeckel, following Vogt, has recently asserted that " matter and ether are not dead, and only moved by extrinsic force; but they are endowed with sensation and will; they experience an inclination for condensation, a dislike for strain they strive after the one and struggle against the other" ("Riddle of the Universe," English translation, I900, p. 380).

But neither unproved assertions of this kind nor the more refined attempts that have been made by others to bring the phenomena of life and of dead matter under a common formula touch the evidence for the atomic theory. The question as to whether matter consists of elements capable of independent motion is prior to and independent of the further questions as to what these elements are, and whether they are alive or dead.

The physicist, if he keeps to his business, asserts, as the bases of the atomic theory, nothing more than that he who declines to admit that matter consists of separate moving parts must regard many of the simplest phenomena as irreconcilable and unintelligible, in spite of the fact that means of reconciling them are known to everybody, in spite of the fact that the reconciling theory gives a general correlation of an enormous number of phenomena in every branch of science, and that the outstanding difficulties are connected, not so much with the fundamental hypotheses that matter is composed of distinguishable entities which are capable of separate motions as with the much more difficult problem of what these entities are.

On these grounds the physicist may believe that, though he cannot handle or see them, the atoms and molecules are as real as the ice crystals in a cirrus cloud which he cannot reach; as real as the unseen members of a meteoric swarm whose deathglow is lost in the sunshine, or which sweep past us, unentangled, in the night.

If the confidence that his methods are weapons with which he can fight his way to the truth were taken from the scientific explorer, the paralysis which overcomes those who believe that they are engaged in a hopeless task would fall upon him.

Physiology has specially flourished since physiologists have believed that it is possible to master the physics and chemistry of the framework of living things, and since they have abandoned the attitude of those who placed in the foreground the doctrine of the vital force. To supporters of that doctrine the principle of life was not a hidden directing power which could perhaps whisper an order that the flood-gates of reservoirs of energy should now be opened and now closed, and could, at the most, work only under immutable conditions to which the living and the dead must alike submit. On the contrary, their vital force pervaded the organism in all its parts. It was an active and energetic opponent of the laws of physics and chemistry. It maintained its own existence not by obeying but by defying them; and though destined to be finally overcome in the separate campaigns of which each individual living creature is the scene, yet like some guerilla chieftain it was defeated here only to reappear there with unabated confidence and apparently un. diminished force.

This attitude of mind checked the advance of knowledge. Difficulty could be evaded by a verbal formula of explanation which in fact explained nothing. If the mechanical, or physical, or chemical causes of a phenomenon did not lie obviously upon the surface, the investigator was tempted to forego the toil of searching for them below; it was easier to say that the vital force was the cause of the discrepancy, and that it was hopeless to attempt to account for the action of a principle which was incomprehensible in its nature.

For the physicist the danger is no less serious, though it lies

NO. I663, VOL. 64$]$ 
in a somewhat different direction. At present he is checked in his theories by the necessity of making them agree with a comparatively small number of fundamental hypotheses. If this check were removed, his fancy might run riot in the wildest speculations, which would be held to be legitimate if only they led to formulæ in harmony with facts. But the very habit of regarding the end as everything, and the means by which it was attained as unimportant, would prevent the discovery of those fragments of truth which can only be uncovered by the painful process of trying to make inconsistent theories agree, and using all facts, however remote, as the tests of our central generalisation.

"Science," said Helmholtz, "Science, whose very object it it is to comprehend Nature, must start with the assumption that Nature is comprehensible." And again, "The first principle of the investigator of Nature is to assume that Nature is intelligible to us, since otherwise it would be foolish to attempt the investigation at all." These axioms do not assume that all the secrets of the universe will ultimately be laid bare, but that a search for them is hopeless if we undertake the quest with the conviction that it will be in vain. As applied to life, they do not deny that in living matter something may be hidden which neither physics nor chemistry can explain, but they assert that the action of physical and chemical forces in living bodies can never be understood, if at every difficulty and at every check in our investigations we desist from further attempts in the belief that the laws of physics and chemistry have been interfered with by an incomprehensible vital force. As applied to physics and chemistry, they do not mean that all the phenomena of life and death will ultimately be included in some simple and self-sufficing mechanical theory they do mean that we are not to sit down contented with paradoxes such as that the same thing can fill both a large space and a little one ; that matter can act where it is not, and the like, if by some reasonable hypothesis, capable of being tested by experiment, we can avoid the acceptance of these absurdities. Something will have been gained if the more obvious difficultie are removed, even if we have to admit that in the background there is much that we cannot grasp.

\section{The Limits of Physical Theories.}

And this brings me to my last point. It is a mistake to treat physical theories in general, and the atomic theory in particular, as though they were parts of a scheme which has failed if it leaves anything unexplained, which must be carried on indefinitely on exactiy the same principles, whether the ultimate results are, or are not, repugnant to common-sense.

Physical theories begin at the surface with phenomena which directly affect our senses. When they are used in the attempt to penetrate deeper into the secrets of Nature, it is more than probable that they will meet with insuperable barriers, but this fact does not demonstrate that the fundamental assumptions are false, and the question as to whether any particular obstacle will be for ever insuperable can rarely be answered with certainty.

Those who belittle the ideas which have of late governed the advance of scientific theory too often assume that there is no alternative between the opposing assertions that atoms and the ether are mere figments of the scientific imagination, or that, on the other hand, a mechanical theory of the atoms and of the ether, which is now confessedly imperfect, would, if it could be perfected, give us a full and adequate representation of the underlying realities.

For my own part I believe that there is a via media.

A man peering into a darkened room, and describing what he thinks he sees, may be right as to the general outline of the objects he discerns, wrong as to their nature and their precise forms. In his description fact and fancy may be blended, and it may be difficult to say where the one ends and the other begins; but even the fancies will not be worthless if they are based on a fragment of truth, which will prevent the explorer from walking into a looking-glass or stumbling over the furniture. He who saw "men as trees walking" had at least a perception of the fundamental fact that something was in motion around him.

And so, at the beginning of the twentieth century, we are neither forced to abandon the claim to have penetrated below the surface of Nature, nor have we, with all our searching, torn the veil of mystery from the world around us.

The range of our speculations is limited both in space and time : in space, for we have no right to claim, as is sometimes done, a knowledge of the "infinite universe" ; in time, for the cumulative effects of actions which might pass undetected in the short span of years of which we have knowledge, may, if continued long enough, modify our most profound generalisations. If some such theory as the vortex-atom theory were true, the faintest trace of viscosity in the primordial medium would ultimately destroy matter of every kind. It is thus a duty to state what we believe we know in the most cautious terms, but it is equally a duty not to yield to mere vague doubts as to whether we can know anything.

If no other conception of matter is possible than that it consists of distinct physical units - and no other conception has been formulated which does not blur what are otherwise clear and definite outlines - if it is certain, as it is, that vibrations travel through space which cannot be propagated by matter, the two foundations of physical theory are well and truly laid. It may be granted that we have not yet framed a consistent image either of the nature of the atoms or of the ether in which they exist; but I have tried to show that in spite of the tentative nature of some of our theories, in spite of many outstanding difficulties, the atomic theory unifies so many facts, simplifies so much that is complicated, that we have a right to insist-at all events till an equally intelligible rival hypothesis is producedthat the main structure of our theory is true ; that atoms are not merely helps to puzzled mathematicians, but physical realities.

SECTION A.

MATHEMATICS AND PHYSICS.

Opening Address by Major P. A. MacMahon, D.Sc., F.R.S., President of THE Section.

DURING the seventy meetings of the Association a pure mathematician has been president of Section $\mathbf{A}$ on ten or a dozen occasions. A theme taken by many has been a defence of the study of pure mathematics. I take Cayley's view expressed before the whole Association at Southport in 1883, that no defence is necessary, but were it otherwise, I feel that nothing need be added to the eloquent words of Sylvester in I 869 and of Forsyth in 1897 . I intend, therefore, to make some remarks on several matters which may be interesting to the Section even at the risk of being considered unduly desultory.

Before commencing I must remark that during the twelve months that have elapsed since the Bradford Meeting we have lost several great men whose lives were devoted to the subjects of this Section. Hermite, the veteran mathematician of France, has left behind him a splendid record of purely scientific work. His name will be always connected with the herculean achievement of solving the general quintic equation by means of elliptic modular functions. Other work, if less striking, is equally of the highest order, and his treatise "Cours d'Analyse" is a model of style. Of Fitzgerald of Dublin it is not easy to speak in this room without emotion. For many years he was the life and soul of this Section. His enthusiasm in regard to all branches of molecular physics, the force and profundity of his speech, the vigour of his advocacy of particular theories, the acute thinking which enabled him to formulate desiderata, his warm interest in the work of others, and the unselfish aid he was so willing to give, are fresh in our remembrance. Rowland was in the forefront of the ranks of physicists. His death at a comparatively early age terminates the important series of discoveries which were proclaimed from his laboratory in the Johns Hopkins University at Baltimore. In Viriamu Jones we have lost an assiduous worker at physics whose valuable contributions to knowledge indicated his power to do much more for science. In Tait, Scotland possessed a powerful and original investigator. The extent and variety of his papers are alike remarkable, and in his collected works there exists an imperishable monument to his fame.

It is interesting, in this the first year of the new century, to take a rapid glance at the position that mathematicians of this country held amongst mathematicians a hundred years ago. During the greater part of the eighteenth century the study of mathematics in England, Scotland and Ireland had been at a very low ebb. Whereas in 1801 on the Continent there were the leaders Lagrange, Laplace and Lagendre, and of rising men, Fourier, Ampère, Poisson and Gauss, we could only clairn Thomas Young and Ivory as men who were doing notable work in research. A mongst schoslboys of various

No. I663, VOL. 64] 
ages we note Fresnel, Bessel, Cauchy, Chasles, Lamé, Möbius, v. Staudt and Steiner on the Continent, and Babbage, Peacock, John Herschel, Henry Parr Hamilton and George Green in this country. It was not, indeed, till about 1845 , or a little later, that we could point to the great names of William Rowan Hamilton, MacCullagh, Adams, Boole, Salmon, Stokes, Sylvester, Cayley, William Thomson, H. J. S. Smith and Clerk Maxwell as adequate representatives of mathematical science. It is worthy of note that this date, 1845 , marks also the year of the dissolution of a very interesting society, the Mathematical Society of Spitalfields ; and I would like to pause a moment, and, if I may say so, rescue it from the oblivion which seems to threaten it. In I80r it was already a venerable institution, having been founded by Joseph Middleton, a writer of mathematical text-books, in $1717,{ }^{1}$ The members of the Society at the beginning were for the most part silk-weavers of French extraction; it was little more than a working man's club, at which questions of mathematics and natural philosophy were discussed every Saturday evening. The number of members was limited to the "square of seven," but later it was increased to the "square of eight," and later still to the "square of nine." In 1725 the place of meeting was changed from the Monmouth's Head to the White Horse in Wheeler Street, and in 1735 to the Ben Jonson's Head in Pelham Street. The sub. scription was six-and-sixpence a quarter, or sixpence a week, and entrance was gained by production of a metal ticket, which had the proposition of Pythagoras engraved on one side and a sighted quadrant with level on the other. The funds, largely augmented by an elaborate system of fines, were chiefly used for the purchase of books and philosophical apparatus. A president, treasurer, inspector of instruments, and secretary were appointed annually, and there were, besides, four stewards, six auditors and six trustees. By the constitution of the Society it was the duty of every member, if he were asked any mathematical or philosophical question by another member, to instruct him to the best of his ability. It was the custom for each member in rotation to lecture or perform experiments on each evening of meeting. There was a fine of half-a-crown for introducing controverted points of divinity or politics. The members dined together twice annually, viz. on the second Friday in January in London in commemoration of the birth of Sir Isaac Newton (this feast frequently took place at the Black Swan, Brown's Lane, Spitalfields), and on the second Friday in July " at a convenient distance in the country in commemoration of the birth of the founder." The second dinner frequently fell through because the members could not agree as to the locality. It was found necessary to introduce a rule fining members sixpence for letting off fireworks in the place of meeting. Every member present was entitled to a pint of beer at the common expense, and, further, every five members were entitled to call for a quart for consumption at the meeting. Such were some of the quaint regulations fin force when about the year 1750 the Society moved to larger apartments in Crispin Street, where it remained without interruption till 1843 . It appears from the old minute books that about the year $175^{\circ}$ the Society absorbed a small mathematical society which used to meet at the Black Swan, Brown's Lane, above mentioned, and that in 1783 an ancient historical society was also incorporated with it. By the year 1800 the class of the members had become improved, and we find some well-known names, such as Dolland, Simpson, Saunderson, Crossley, Paroissen and Gompertz. At the time lectures were given in all branches of science 'by the members in the Society's rooms, which on these occasions were open to the public on payment of one shilling. The arrangements for the tsession $1822-23$ included lectures in mechanics, hydrostatics and hydraulics, pneumatics, optics, astronomy, chemistry, electricity, galvanism, magnetism and botany, illustrated by experiments. On account of these lectures the Society had to fight an action-at-law, and although the case was won, its slender resources were crippled for many years. In I827 Benjamin Gompertz, F.R.S., succeeded to the presidency on the death of the Rev. George Paroissen. From the year 1830 on wards the membership gradually declined and the financial outlook became serious. In 1843 there was a crisis ; the Society left Crispin Street for cheaper rooms at 9 Devonshire Street, Bishopsgate Street, and finally, in 1845, after a

1 Its first place of meeting was the Monmouth's Head, Monmouth Street, Spitalfields. This street has long disappeared. From a map of London of orresponded to the present Wilks Street.

No. I $66_{3}$, VOL, 64$]$ futile negotiation with the London Institution, it was taken over by the Royal Astronomical Society, which had been founded in 182r. The library and documents were accepted and the few surviving members were made life members of the Astronomical Society without payment. So perished this curious old institution; it had amassed a really valuable library containing books on all branches of science. The Astronomica Society has retained the greater part, but some have found their way to the libraries of the Chemical and other societies. An inspection of the documents establishes that it was mainly a society devoted to physics, chemistry and natural history. It had an extensive museum of curiosities and specimens of natural history, presented by individual members, which seems to have disappeared when the rooms in Crispin Street were vacated. It seems a pity that more effort was not made to keep the old institution alive. The fact is that at that date the Royal Society had no sympathy with special societies and did all in its power to discourage them. The Astronomical Society was only formed in $182 \mathrm{I}$ in the teeth of the opposition of the Royal Society.

Reverting now to the date 1845 , it may be said that from this period to I 866 much good work emanated from this country, but no Mathematical Society existed in London. At the latter date the present Society was formed, with De Morgan as its first president. Gompertz was an original member, and the only person who belonged to both the old and new societies. The thirty-three volumes of Proceedings that have appeared give a fair indication of the nature of the mathematical work that has issued from the pens of our countrymen. All will admit that it is the duty of any one engaged in a particular line of research to keep himself abreast of discoveries, inventions, methods and ideas, which are being brought forward in that line in his own and other countries. In pure science this is easier of accomplishment by the individual worker than in the case of applied science. In pure mathematics the stately edifice of the Theory of Functions has, during the latter part of the century which has expired, been slowly rising from its foundations on the continent of Europe. It had reached a considerable height and presented an imposing appearance before it attracted more than superficial notice in this country and in America. It is satisfactory to note that during recent years much of the leeway has been made up. English-speaking mathematicians have introduced the first notions into elementary text-books; they have written advanced treatises on the whole subject; they have encouraged the younger men to attend courses of lectures in foreign universities; so that to-day the best students in our universities can attend courses at home given by competent persons, and have the opportunity of acquiring adequate knowledge, and of themselves contributing to the general advance. The Theory of Functions, being concerned with the functions that satisfy differential equations, has attracted particularly the attention of those whose bent seemed to be towards applied mathematics and mathematical physics, and there is no doubt, in analogy with the work of Poincaré in celestial dynamics, those sciences will ultimately derive great benefit from the new study. If, on the other hand, one were asked to specify a department of pure mathematics which has been treated somewhat coldly in this country during the last quarter of the last century, one could point to geometry in general, and to pure geometry, descriptive geometry and the theory of surfaces in particular. This may doubtless be explained by the circumstance that, at the present time, the theory of differential equations and the problems that present themselves in their discussion are of such commanding importance from the point of view of the general advance of mathematical science that those subjects naturally prove to be most attractive.

As regards organisation and cooperation in mathematics, Germany, I believe, stands first. The custom of offering prizes for the solutions of definite problems which are necessary to the general advance obtains more in Germany and in France than here, where, I believe, the Adams Prize stands alone. The idea has an indirect value in pointing out some of the more pressing desiderata to young and enthusiastic students, and a direct importance in frequently, as it proves, producing remarkable dissertations on the proposed questions. The field is so vast that any comprehensive scheme of cooperation is scarcely possible, though much more might be done with advantage.

If we turn our eyes to the world of astronomy we find there a grand scheme of cooperation which other departments may indeed envy. The gravitation formula has been recognised from the time of Newton as ruling the dynamics of the heavens, and the exact agreement of the facts derived from observation with 
the simple theory has established astronomy as the most exact of all the departments of applied science. Men who devote themselves to science are actuated either by a pure love of truth or because they desire to apply natural knowledge to the benefit of mankind. Astronomers belong, as a rule, to the first category, which, it must be admitted, is the more purely scientific. We not only find international cooperation in systematically mapping the universe of stars and keeping all portions of the universe under constant observation, but also when a particular object in the heavens presents itself under circumstances of peculiar interest or importance, the observatories of the world combine to ascertain the facts in a manner which is truly remarkable. As an illustration, I will instance the tiny planet Eros discovered a few years ago by De Witt. Recently the planet was in opposition and more favourably situated for observation than it will be again for thirty years. It was determined, at a conference held in Paris in July 1900, that combined work should be undertaken by no fewer than fifty observatories in all parts of the world. Beyond the fixing of the elements of the mean motion and of the perturbations of orbit due to the major planets, the principal object in view is the more accurate determination of solar parallax. To my mind this concert of the world, this cosmopolitan association of fine intellects, fine instruments, and the best known methods, is a deeply impressive spectacle and a grand example of an ideal scientific spirit. Other sciences are not so favourably circumstanced as is astronomy for work of a similar kind undertaken in a similar spirit. If in comparison they appear to be in a chaotic state, the reason in part must be sought for in conditions inherent to their stady, which make combined work more difficult, and the results of such combined work as there is less striking to spectators. Still, the illustration I have given is a useful object-lesson to all men of science, and may encourage those who have the ability and the opportunity to make strenuous efforts to further progress by bringing the work of many to a single focus.

In pure science we look for a free interchange of ideas, but in applied physics the case is otherwise, owing to the fact that the commercial spirit largely enters into them. In a recent address, Prof. Perry has stated that the standard of knowledge in electrical engineering in this country is not as high as it is elsewhere, and all men of science and many men in the street know that he is right. This is a serious state of affairs, to which the members of this Section cannot be in any sense indifferent. We cannot urge that it is a matter with which another Section of the Association is concerned to a larger degree. It is our duty to take an active, and not merely passive attitude toward this serious blot on the page of applied science in England. For this many reasons might be given, but it is sufficient to instance one, and to state that neglect of electrical engineering has a baneful effect upon research in pure science in this country. It hinders investigations in pure physics by veiling from observation new phenomena which arise naturally, and by putting out of our reach means of experimenting with new combinations on a large scale. Prof. Perry has assigned several reasons for the present impasse, viz., a want of knowledge of mathematics on the part of the rising generation of engineers; the bad teaching of mathematics, and antiquated methods of education generally want of recognition of the fact that engineering is not on stereotyped lines, but, in its electrical aspect, is advancing at a prodigious rate; municipal procrastination, and so on. He confesses, moreover, that he does not see his way out of the difficulty, and is evidently in a condition of gloomy apprehension.

It is, I think, undoubted that science has been neglected in this country, and that we are reaping as we have sowed. The importance of science teaching in secondary schools has been overlooked. Those concerned in our industries have not seen the advantage of treating their workshops and manufactories as laboratories of research. The Government has given too meagre an endowment to scientific institutions, and has failed to adequately encourage scientific men and to attract a satisfactory quota of the best intellects of the country to the study of science. Moreover, private benefactors have not been as numerous as in some other countries in respect of those departments of scientific work which are either non-utilitarian or not immediately or obviously so. We have been lacking alike in science organisation and in effective cooperation in work.

It has been attempted to overcome defects in training for scientific pursuits by the construction of royal roads to scientific knowledge. Engineering students have been urged to forego the study of Euclid, and, as a substitute, to practise drawing triangles and squares; it has been pointed out to them that mathematical study has but one object, viz., the practical carry ing out of mathematical operations ; that a collection of mathematical rules of thumb is what they should aim at ; that a knowledge of the meaning of processes may be left out of account so long as a sufficient grasp of the application of the resulting rules is acquired. In particular, it has been stated that the study of the fundamental principles of the infinitesimal calculus may be profitably deferred indefinitely so long as the student is able to differentiate and integrate a few of the simplest functions that are met with in pure and applied physics. The advocates of these views are, to my mind, urging a process of "cramming" for the work of life which compares unfavourably with that adopted by the so-called "crammers" for examinations; the latter $\mathrm{I}$ believe to be, as a rule, much maligned individuals, who succeed by good organisation, hard work and personal influence, where the majority of public and private schools fail ; the examinations for which their students compete encourage them to teach their pupils to think, and not to rely principally upon remembering rules. The best objects of education, I believe, are the habits of thought and observation, the teaching of how to think, and the cultivation of the memory; and examiners of experience are able to a considerable extent to influence the teaching in these respects ; they show the teachers the direction in which they should look for success. The result has been that the "crammer" for examinations, if he ever existed, has disappeared. But what can be said for the principle of cramming for the work of one's life? Here an examination would be no check, for examiners imbued with the same notion would be a necessary part of the system; the awakening of the student would come, perhaps slowly, but none the less inevitably; he might exist for a while on his formulæ and his methods, but with the march of events, resulting in new ideas, new apparatus, new designs, new inventions, new materials requiring the utmost development of the powers of the mind, he will certainly find himself hopelessly at sea and in constant danger of discovering that he is not alone in thinking himself an impostor. And an impostor he will be if he does not by his own assiduity cancel the pernicious effects of the system upon which he has been educated. I do not, I repeat, believe in royal roads, though I appreciate the advantage of easy coaches in kindred sciences. In the science to which a man expects to devote his life, the progress of which he hopes to further, and in which he looks for his life's success, there is no royal road. The neglect of science is not to be remedied by any method so repugnant to the scientific spirit; we must take the greater, knowing that it includes the less, not the less, hoping that in some happy-golucky way the greater will follow.

At the beginning of the nineteenth century it was possible for most workers to be well acquainted with nearly all important theories in any division of science; the number of workers was not great, and the results of their labours were for the most part concentrated in treatises and in a few publications especially devoted to science; it was comparatively easy to follow what was being done. At the present time the state of affairs is different. The number of workers is very large; the treatises and periodical scientific journals are very numerous; the ramifications of investigation are so. complicated that it is scarcely possible to acquire a competent knowledge of the progress that is being mar?e in more than a few of the subdivisions of any division of science. Hence the so-called specialist has come into being.

Evident though it be that this is necessarily an age of specialists, it is curious to note that the word "specialist" is often used as a term of opprobrium, or as a symbol of narrow. mindedness. It has been stated that most specialists run after scientific truth in intellectual blinkers; that they wilfully restrain themselves from observing the work of others who may be even in the immediate neighbourhood; that even when the line of pursuit intersects obviously other lines, such intersection is passed by without remark; that no attention is paid to the existence or the construction of connecting lines; that the necessity for collaboration is overlooked; that the general advance of the body of scientific truth is treated as of no concern; that absolute independence of aim is the thing most to be desired. I propose to inquire into the possibility of such an individual existing as a scientific man.

I take as a provisional definition of a specialist in science one who devotes a very large proportion of his energies to 
original research in a particular subdivision of his subject. It will be sufficient to consider the subjects that come under the purview of Section A; though it will be obvious that a similar train of reasoning would have equal validity in connection with the subjects included in any of the other sections. I take the word "specialist" to denote a man who makes original discoveries in some branch of science, and I deny that any other man has the right, in the modern meaning of the word, to be called by others, or to call himself, a specialist. I would not wish to be understood to imply a belief that a truly scientific man is necessarily a specialist; I do believe that a scientific man of high type is almost invariably an original discoverer in one or more special branches of science ; but I can conceive that a man may study the mutual relations of different sciences and of different branches of the same science and may throw such an amount of light upon the underlying principles as to be in the highest degree scientific. I will now advance the proposition that, with this exception, all scientific workers are specialists; it is merely a question of degree. An extreme specialist is that man who makes discoveries in only one branch, perhaps a very narrow branch, of his subject. I shall consider that in defending him I am a fortiori defending the man who is a specialist, but not of this extreme character.

A subject of study may acquire the reputation of being narrow either because it has for some reason or other not attracted workers and is in reality virgin soil only awaiting the arrival of a husbandman with the necessary skill, or because it is an extremely difficult subject which has resisted previous attempts to elucidate it. In the latter case, it is not likely that a scientific man will obstinately persist in trying to force an entrance through a bare blank wall. Either from weariness in striving or from the exercise of his judgment he will turn to some other subdivision which appears to give greater promise of success. When the subject is narrow merely because it has been overlooked, the specialist has a grand opportunity for widening it and freeing it from the reproach of being narrow ; when it is narrow from its inherent difficulty he has the opportunity of exerting his full strength to pierce the barriers which close the way to discoveries. In either case the specialist, before he can determine the particular subject which is to engage his thoughts, must have a fairly wide knowledge of the whole of his subject. If he does not possess this he will most likely make a bad choice of particular subjects, or, having made a wise selection, he will lack an essential part of the mental equipment necessary for a successful investigation. Again, though the subject may be a narrow one, it by no means follows that the appropriate or possible methods of research are prescribed within narrow limits. I will instance the Theory of Numbers, which, in comparatively recent times, was a subject of small extent and of restricted application to other branches of science. The problems that presented themselves naturally, or were brought into prominence by the inaginations of great intellects, were fraught with difficulty. There seemed to be an absence, partial or complete, of the law and order that investigators had been accustomed to find in the wide realm of continuous quantity. The country to be explored was found to be full of pitfalls for the unwary. Many a lesson concerning the danger of hasty generalisation had to be learnt and taken to heart. Many a false step had to be retraced. Many a road which a first reconnaissance had shown to be straight for a short distance was found, on further exploration, to change suddenly its direction and to break up into a number of paths which wandered in a fitful manner in country of increasing natural difficulty. There were few vanishirg points in the perspective. Few, also, and insignifican were the peaks from which a general notion could be gathered of any considerable portion of the country. The surveying instruments were inadequate to cope with the physical characters of the land. The province of the Theory of Numbers was forbidding. Many a man returned empty-handed and baffled from the pursuit, or else was drawn into the vortex of a kind of maelström and had his heart crushed out of him. But early in the last century the dawn of a brighter day was breaking. A combination of great intellects-Legendre, Gauss, Eisenstein, Stephen Smith, \&c. - -succeeded in adapting some of the existing instruments of research in continuous quantity to effective use in discontinuous quantity. These adaptations are of so difficult and ingenious a nature that they are to-day, at the commencement of a new century, the wonder and, I may add, the delight of beholders. True it is that the beholders are few. To attain to the point of vantage is an arduous task demanding alike devotion and courage. I am reminded, to take a geographical analogy, of the Hamilton Falls, near Hamilton Inlet, in Labrador. I have been informed that to obtain a view of this wonderful natural feature demands so much time and intrepidity, and necessitates so many collateral arrangements, that a few years ago only nine white men had feasted their eyes on falls which are finer than those of Niagara. The labours of the mathematicians named have resulted in the formation of a large body of doctrine in the Theory of Numbers. Much that, to the superficial observer, appears to lie on the threshold of the subject is found to be deeply set in it and to be only capable of attack after problems at first sight much more com plicated have been solved. The mirage that distorted the scenery and obscured the perspective has been to some extent dissipated; certain vanishing points have been ascertained; certain elevated spots giving extensive views have been either found or constructed. The point I wish to urge is that these specialists in the Theory of Numbers were successful for the reason that they were not specialists at all in any narrow meaning of the word. Success was only possible because of the wide learning of the investigator; because of his accurate knowledge of the instruments that had been made effective in other branches; because he had grasped the underlying principles which caused those instruments to be effective in particular cases. I am confident that many a worker who has been the mark of sneer and of sarcasm from the supposed extremely special character of his researches would be found to have devoted the larger portion of his time to the study of methods which had been available in other branches, perhaps remote from the one which was particularly attracting his attention. $\mathrm{He}$ would be found to have realised that analogy is often the finger-post that points the way to useful advance ; that his mind had been trained and his work assisted by studying exhaustively the successes and failures of his fellow-workers. But it is not only existing methods that may be available in a special research.

Furthermore, a special study frequently creates new methods which may be subsequently found applicable in other branches. The Theory of Numbers furnishes several beautiful illustrations of this. Generally, the method is more important than the immediate result. Though the result is the offspring of the method, the method is the offspring of the search after the result. The Law of Quadratic Reciprocity, a cornerstone of the edifice, stands out not only for the influence it has exerted in many branches, but also for the number of new methods to which it has given birth, which are now a portion of the stock-in-trade of a mathematician. Euler, Legendre, Gauss, Eisenstein, Jacobi, Kronecker, Poincaré and Klein are great names that will be for ever associated with it. Who can forget the work of H. J. S. Smith on homo. geneous forms and on the five-square theorem, work which gave rise to processes that have proved invaluable over a wide field, and which supplied many connecting links between departments which were previously in more or less complete isolation?

In this connection I will further mention two branches with which I may claim to have a special acquaintance-the theory of invariants and the combinatorial analysis. The theory of invariants was evolved by the combined efforts of Boole, Cayley, Sylvester and Salmon, and has progressed during the last sixty years with the cooperation, amongst others, of Aronhold, Clebsch, Gordan, Brioschi, Lie, Klein, Poincaré, Forsyth, Hilbert, Elliott and Young, It involves a principle which is of wide significance in all the subject-matters of inorganic science, of organic science, and of mental, moral and political philosophy. In any subject of inquiry there are certain entities, the mutual relations of which under various conditions it is desirable to ascertain. A certain combination of these entities may be found to have an unalterable value when the entities are submitted to certain processes or are made the subjects of certain operations. The theory of invariants in its widest scientific meaning determines these combinations, elucidates their properties, and expresses results when possible in terms of them. Many of the general principles of political science and economics can be expressed by means of invariantive rela. tions connecting the factors which enter as entities into the special problems. The great principle of chemical science which asserts that when elementary or compound bodies combine with one another the total weight of the materials is unchanged,

NO. I663, VOL. 64$]$ 
is another case in point. Again, in physics, a given mass of gas under the operation of varying pressure and temperature has the well-known invariant, pressure multiplied by volume and divided by absolute temperature. Examples might be multiplied. In mathematics the entities under examination may be arithmetical, algebraical, or geometrical ; the processes to which they are subjected may be any of those which are met with in mathematical work. It is the principle which is so valuable. It is the idea of invariance that pervades to-day all branches of mathematics. It is found that in investigations the invariantive fractions are those which persist in presenting themselves, even when the processes involved are not such as to ensure the in. variance of those functions. Guided by analogy may we not anticipate similar phenomena in other fields of work?

The combinatorial analysis may be described as occupying an extensive region between the algebras of discontinuous and continuous quantity. It is to a certain extent a science of enumeration, of measurement by means of integers as opposed to measurement of quantities which vary by infinitesimal increments. It is also concerned with arrangements in which difference of quality and relative position in one, two, or three dimensions are factors. Its chief problem is the formation of connecting roads between the sciences of discontinuous and continuous quantity. To enable, on the one hand, the treatment of quantities which vary per saltum, either in magnitude or position, by the methods of the science of continuously varying quantity and position, and on the other hand to reduce problems of continuity to the resources available for the management of discontinuity. These two roads of research should be regarded as penetrating deeply into the domains which they connect.

In the early days of the revival of mathematical learning in Europe the subject of "combinations" cannot be said to have rested upon a scientific basis. It was brought forward in the shape of a number of isolated questions of arrangement, which were solved by mere counting. Their solutions did not further the general progress, but were merely valuable in connection with the special problems. Life and form, however, were infused when it was recognised by De Moivre, Bernoulli and others that it was possible to create a science of probability on the basis of enumeration and arrangement. Jacob Bernoulli, in his "Ars Conjectandi," I713, established the fundamental principles of the Calculus of Probabilities. A systematic advance in certain questions which depend upon the partitions of numbers was only possible when Euler showed that the identity $x^{a} x^{b}=x^{a+b}$ reduced arithmetical addition to algebraical multiplication and vice versâ. Starting with this notion, Euler developed a theory of generating functions on the expansion of which depended the formal solutions of many problems. The subsequent work of Cayley and Sylvester rested on the same idea, and gave rise to many improvements. The combinations under enumeration had all to do with what may be termed arrangements on a line subject to certain laws. The results were important algebraically, as throwing light on the theory of Algebraic series, but another large class of problems remained untouched, and was considered as being both outside of the scope and beyond the power of the method. I propose to give some account of these problems, and to give a short history of the way in which a method of solution has been reached. It will be gathered from remarks made above that I regard any department of scientific work which seems to be narrow or isolated as a proper subject for research. I do not believe in any branch of science or subject of scientific work being destitute of connection with other branches. If it appears to be so, it is especially marked out for investigation by the very unity of science. There is no necessarily pathless desert separating different regions. Now a department of pure mathematics which appeared to be somewhat in this forlorn condition a few years ago was that which included problems of the nature of the magic square of the ancients. Conceive a rectangular lattice or generalised chess board ( $c f$. "Gitter," Klein), whose compartments are situations for given numbers or quantities, so that there is a rectangular array of certain entities. The general problem is the enumeration of the arrays when both the rows and the columns of the lattice satisfy certain conditions. With the simplest of such problems certain progress had undoubtedly been made. The article on Magic Squares in the "Encyclopæedia Britannica" and others on the same subject in various scientific publications are examples of such progress, but the position of isolation was not sensibly ameliorated. Again, the well-known "problème des rencontres" is an instance in point. Here the problem is to place a number of different entities in an assigned order in a line and beneath them the same entities in a different order subject to the condition that the entities in the same vertical line are to be different. This easy question has been solved by generating functions, finite differences, and in many other ways. In fact, when the number of rows is restricted to two the difficulties inherent in the problem when more than two rows are in question do not present themselves. The problem of the Latin Square is concerned with a square of order $n$ and $n$ different quantities which have to be placed one in each of the $n^{2}$ compartments in such wise that each row and each column contains each of the quantities. The enumeration of such arrangements was studied by mathematicians from Euler to Cayley without any real progress being made. In reply to the remark "Cui bono?"I should say that such arrangements have presented themselves for investigation in other branches of mathematics. Symbolical algebras and in particular the theory of discontinuous groups of operations have their laws defined by what Cayley has termed a multiplication table. Such multiplication tables are necessarily Latin Squares, though it is not conversely true that every Latin Square corresponds to a multiplication table. One of the most important questions awaiting solution in connection with the theory of finite discontinuous groups is the enumeration of the types of groups of given order or of Latin Squares which satisfy additional conditions. It thus comes about that the subject of Latin Squares is important in mathematics, and some new method of dealing with them seemed imperative.

A fundamental idea was that it might be possible to find some mathematical operation of which a particular Latin Square might be the diagrammatic representative. If, then, a one-to-one correspondence could be established between such mathematical operations and the Latin Squares, the enumeration might conceivably follow. Bearing this notion in mind, consider the differentiation of $x^{n}$ with regard to $x$. Noticing that the result is $n x^{n-1}$ ( $n$ an integer), let us inquire whether we can break up the operation of differentiation into $n$ elementary portions, each of which will contribute a unit to the resulting coefficient $n$. If we write down $x^{n}$ as the product of $n$ letters, viz. $x x x x \ldots$. . it is obvious that if we substitute unity in place of a single $x$ in all possible ways, and add together the results, we shall obtain $n x^{n-1}$. We have, therefore, $n$ different elementary operations, each of which consists in substituting unity for $x$. We may denote these diagrammatically by

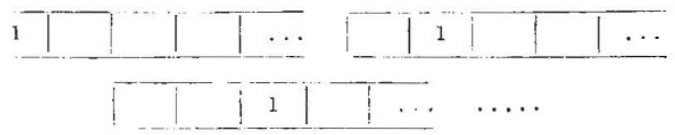

and from this point of view $\frac{d}{d x}$ is a combinatorial symbol, and

denotes by the coefficient $n$ the number of ways of selecting one out of $n$ different things.

Similarly, the higher differentiations give rise to diagrams of two or more rows, the numbers of which are given by the co. efficients which result from such differentiations. Following up this clue much progress has been made. For a particular problem success depends upon the design, on the one hand, of a function, on the other hand, of an operation such that diagrams make their appearance which have a one-to one correspondence with the entities whose enumeration is sought. For a general investigation, however, it is more scientific to start by designing functions and operations, and to then ascertain the problems of which the solution is furnished. The difficulties connected with the Latin Square and with other more general questions have in this way been completely overcome.

The second new method in analysis that I desire to bring before the Section had its origin in the theory of partition. Diophantus was accustomed to consider algebraical questions in which the symbols of quantity were subject to certain conditions, such, for instance, that they must denote positive numbers or integer numbers. A usual condition with him was that the quantities must denote positive integers. All such problems, and particularly those last specified, are qualified by the adjective Diophantine. The partition of numbers is then on all fours with the Diophantine equation

$$
a+\beta+\gamma+\ldots+\nu=n,
$$


a further condition being that one solution only is given by a group of numbers $\alpha, \beta, \gamma$. . satisfying the equation; that in fact permutations amongst the quantities $a, \beta, \gamma \ldots$ are not to be taken into account. This further condition is brought in analytically by adding the Diophantine inequalities

$$
a \geq \beta \geq \gamma \geq \ldots \geq \nu \geq 0
$$

$\nu$ in number. The importation of this idea leads to valuable results in the theory of the subject which suggested it. A generating function can be formed which involves in its construction the Diophantine equation and inequalities, and leads after treatment to a representative as well as enumerative solution of the problem. It enables further the establishment of a group of fundamental parts of the partitions from which all possible partitions of numbers can be formed by addition with repetition. In the case of simple unrestricted partition it gives directly the composition by rows of units which is in fact carried out by the Ferrers-Sylvester graphical representation and has led in the hands of the latter to important results in connection with algebraical series which present themselves in elliptic functions and in other departments of mathematics. Other branches of analysis and geometry supply instances of the value of extreme specialisation.

What we require is not the disparagement of the specialist but the stamping out of narrow-mindedness and of ignorance of the nature of the scientific spirit and of the life-work of those who devote their lives to scientific research. The specialist who wishes to accomplish work of the highest excellence must be learned in the rescurces of science and have constantly in mind its grandeur and its unity.

\section{SECTION D.}

\section{ZOOLOGY.}

Opening Address by Prof. J. Cossar Ewart, M.D., F.R.S., President of THE Section.

\section{The Experimental Study of Variation.}

THE study of variation may be said to consist (I) in noting and classifying the differences between parents and their offspring; and (2) in determining by observation and experiment the causes of these differences, especially why only some of them are transmitted to future generations. The facts of variation having been dealt with at considerable length in a recent work by Mr. Bateson, I shall discuss chiefly the causes of variation.

Though for untold ages parents have doubtless observed differences in the form and temperament of their children, and though breeders have long noted unlooked-for traits in thei flocks and herds, the systematic study of variation is of very recent date. This is not surprising, for while the belief in the immutability of species prevailed, there was no special incentive either to collect the facts or inquire into the causes of variation; and since the appearance in 1859 of the "Origin of Species" biologists have been mainly occupied in discussing the theory of natural selection. Now that discussions as to the nature and origin of species no longer occupy the chief attention of biologists, variability - the fountain and origin of progressive development-is likely to receive an ever-in creasing amount of notice. Strange as it may appear, naturalists at the end of the eighteenth century concerned themselves more with the causes of variation than their successors at the end of the nineteenth. Buffon, who discussed at some length nearly all the great problems that interest naturalists to day, after considering variation arrived at the conclusion that it was due to the direct action of the environment, and even invented a theory (strangely like Darwin's theory of pangenesis) to explain how somatic were converted into germinal variations. Erasmus Darwin and Lamarck also had views as to the causes of variation. Erasmus Darwin believed variability resulted from the efforts of the individual, new structures being gradually evolved by the organisms constantly endeavouring to adapt themselves to their surroundings. Lamarck about the same time endeavoured to prove that changes in the environment produced new needs, which in turn led to the formation of new organs and the modification of old ones, use being specially potent in perfecting the new, disuse in suppressing the old. Both Erasmus Darwin and Lamarck, without attempting, or apparently even seeing the need of, any such explanation as pangenesis offered, assumed that definite acquired modifications were transmitted to the offspring, and they both further assumed that variations occurred not in many but in a single definite direction; hence they had no need to postulate selection. The speculations of Erasmus Darwin and Lamarck having had little influence, it fell to Charles Darwin to construct new and more lasting foundations for the evolution theory.

Charles Darwin, clearly realising that variation occurs in many different directions, arrived at the far-reaching conclusion that the best adapted varieties are selected by the environment, and thus have a chance of giving rise to new species. Though impressed with the paramount importance of selection, Charles Darwin realised that "its action absolutely depends on what we in our ignorance call spontaneous or accidental variation."] Darwin, however, concerned himself to the last more with selection than with variation, doubtless because he believed variability sinks to a quite subordinate position when compared with natural selection. As variations stand in very much the same relation to selection as bricks and other formed material stand to the builder.-Darwin was perhaps justifed in rating so high the importance of the principle with which his name will ever be intimately associated. Though Darwin considered variability of secondary importance, it may be noted that he did more than any other naturalist to collect the facts of variation, and he moreover considered at some length the causes of variation. He regarded with most favour the view "that variations of all kinds and degrees are directly or indirectly caused by the conditions of life to whieh each being or more especially its ancestors have been exposed." 2 Of all the causes which induce variability, he believed excess of food was probally the most powerful. ${ }^{3}$ In addition to variations which arise spontaneously in obedience to fixed and immutable laws, Darwin believed with Buffon that variations were produced by the direct action of the environment, and with Lamarck by the use and disuse of parts; and he accounted for the inheritance of such variations by his theory of pangenesis. Darwin seems always to have regarded the direct action of the environment and use and disuse as, at the riost, subsidiary causes of variation ; but $\mathrm{Mr}$. Herbert Spencer and his followers regard "use-inheritance" as an all-important factor in evolution; while Cope and his followers in America, by a mixture of "use-inheritance" (Konetogenesis) and Lamarck's neckstretching theory (Archæsthetism), apparently see their way to account for the evolution of animals with but little help from natural selection.

Prof. Weismann and others, however, have recently given strong reasons for the belief that all variation is the result of changes in the germ-plasm ultimately due to external stimuli, the environment acting directly on unicellular, indirectly on multicellular organism. It is convenient to speak of biologists who believe with Mr. Herbert Spencer in the law of use and disuse (use-inheritance) as Neo-Lamarckians, and of those who with Weismann refuse to accept the doctrine of the transmission of definite acquired characters, and in the case of multicellular organisms the direct influence of the environment as a cause of variation, as Neo-Darwinians. In discussing variability I shall assume that all variations are transmitted by the germ-cells; that the primary cause of variation is always the effect of external influences, such as food, temperature, moisture, \&c. ; and that "the origin of a varia. tion is equally independent of selection and amphimixis" (Weismann, "The Germ-Plasm," p. 43I), amphimixis being simply the means by which effect is given to differences inherited, and to the differences acquired by the germ-cells during their growth and maturation.

Theoretically the offspring should be an equal blend of the parents and (because of the tendency to reversion) of their respective ancestors. In as far as the offspring depart either in an old or in a new direction from this ideal intermediate condition they may be said to have undergone variation. The more obvious variations consist of a difference in form, size and colour, in the rate of growth, in the period at which maturity is reached, in the fertility, in the power to withstand disease and changes in the surroundings, of differences in temperament and instincts, and in the aptitude to learn. In the members of a human family there may be great dissimilarity, and the dissimilarity may be even greater in the members of a single brood or litter of domestic animals, especially if the parents belong to slightly different breeds.

1 "Animals and Plants," vol. ii, p. 206.

2 Itid., vol. ii, p. 240. Elsewhere he says we are "driven to the conclusion that in most cases the conditions of life play a subordinate part in causing any particular modification.

3 Ibid., vol. ii, p. 282. NO. I663, VOL. 64] 
Frequently some of the offspring closely resemble the immediate ancestors, while others suggest one or more of the remote ancestors, are nearly intermediate between the parents, or present quite new characters. Similarly seedlings from the same capsule often differ. Can we by way of accounting for these differences only with Darwin say variations are due to fixed and immutable laws, or at the most subscribe to the assertion of Weismann, that they are "due to the constant recurrence of slight inequalities of nutrition of the germ-plasm "? " Germ. Plasm," p. 43I). Weismann accounts for ordinary variation by saying that the reduction of the germ-plasm during the maturation of the germ-cell is qualitative as well as quantitative, i.e. that the germ-plasm retained in the ovum to form the female pro-nucleus is different from the germ-plasm discharged in the second polar body. He accounts for discontinuous variation and "sports" by "the permanent action of uniform changes in nutrition" ("Germ-Plasm," p. 431). These uniform changes in nutrition by modifying in a constant direction susceptible groups of germ-units (determinants) after a time giving rise to new, it may be pronounced variation. Must we rest satisfied with these assumptions, or is it possible to account for some of the variability met with by, say, differences in the maturity of the parents or of the germ-cells, by the germ-cells having been influenced by interbreeding or intercrossing, or by the soma in which they are lodged having been invigorated by a change of food, or habitat, or deteriorated by unfavourable surroundings or disease? In other words, are there valid reasons for believing that the germ-cells are extremely sensitive to changes in their immediate environment, i.e., to modifications of the body, or soma containing them, and that the characters of the offspring depend to a considerable extent on whether the germ-cells have recently undergone rejuvenescence?

Obviously if the offspring, other things being equal, vary with the age of the parents, the ripeness of the germ-cells and with the bodily welfare, the qualitative division of the nucleus on which Weismann so much relies as an explanation of ordinary variation will prove inadequate.

\section{Is Age a Cause of Variation?}

During the course of my experiments on Variation I endeavoured to find an answer to the question, "Is Age a Cause of Variation?" During development and while nearly all the available nourishment is required for building up the organs and tissues of the body, the germ-cells remain in a state of quiescence. Sooner or later, however, they begin to mature, and eventually in most cases escape from the germ-glands. I find the first germ-cells ripened often prove infertile. When, e.g., pigeons from the same nest are isolated and allowed to breed as soon as mature, they seldom hatch out birds from the first pair of eggs, and though quite vigorous in appearance they may only hatch a single bird from the second pair of eggs. The same result generally follows mating very young but quite unrelated pigeons; but when a young hen bird is mated with a vigorous, well-matured male, or a young male is mated with a vigorous, well-matured female, the eggs generally prove fertile from the first. The germ-cells are, as far as can be determined, structurally perfect from the outset; and that they only fail in vigour is practically proved by the fact that though the conjugation of germ-cells from two young birds leads to nothing, the conjugation of germ-cells from quite young birds with germ. cells from mature birds generally at once results in offspring.

The following experiments indicate how age may prove a cause of variation. Last autumn I received from Islay two young male blue-rock pigeons which, though bred in captivity, were believed to be as pure as the wild birds of the Islay caves. In February last one of the young blue-rocks, while still immature, was placed with an inbred white fantail, the other with an extremely vigorous well-matured black barb. In course of time a pure-white bird was reared by the white fantail, and two dark birds by the black barb. Owing probably to the fantail being inbred and the blue-rock being still barely mature, the young white bird died soon after leaving the nest. No birds were hatched from the second and third pairs of eggs laid by the fantail, but from the fourth pair two birds were hatched which are now nearly full-grown. These young birds are of a darker shade of blue, and look larger and more vigorous than their blue-rock sire. As in the Indian variety of the blue-rock pigeon the croup is blue, and, as in some of the Eastern blue-rocks, the wings are slightly chequered. They, however, only essentially differ from their sire in having four extra feathers in the tail. The first pair of birds hatched by the black barb when they reached maturity early in August might have passed for young barbs with somewhat long beaks. Since the first pair were hatched in March the blue-rock and black barb have reared six other birds. One of the second brood closely resembles the first birds hatched; the other is of a greyish colour, with slightly mottled wings, a long beak, and a tail bar. The birds of the third nest are both of a greyish colour, but have indistinct wing bars as well as a tail bar. Of the fourth pair of young, one is greyish like the birds of the third nest, the other is of a dark blue colour with slightly chequered wings, and a head, beak and bars as in its blue-rock sire. The gradual change from black to dark blue in the blue-rock barb crosses is very remarkable. I can only account for the almost mathematical regularity of the change by supposing it has kept pace with a gradual increase in the vigour or prepotency in the young blue-rock. Eventually the offspring of the blue-rock mated to the black barb, like the offspring of its brother with the white fantail, may be of a slaty blue colour, and otherwise resemble a wild blue-rock pigeon. Many breeders would explain the offspring taking more and more after the sire by the doctrine of Saturation-a doctrine that finds much favour amongst breeders-but as identical results were obtained when young females were mated with well-matured males the saturation explanation falls to the ground.

Like results were obtained by breeding young grey quarterwild rabbits with an old white Angora buck: the first young were white, the subsequent young were white, grey and bluish grey. From these results it follows that when old and young but slightly different members of a variety or species are marked a wonderfully perfect series of intermediate forms is likely to be produced. Amongst wild animals the young males rarely have a chance of breeding with the young females; hence amongst wild animals, owing to age being a cause of variation, a considerable amount of material is doubtless constantly provided for selection, thus affording a variety an additional chance of adapting itself to slight fluctuations in the environment.

In the results obtained by crossing mature, vigorous, and, in some cases, inbred males with barely mature females, an explanation may be found why in some families the same features have persisted almost unaltered for many generations; why in his features the squire of to-day sometimes exactly reproduces the lines of his ancestors, as seen in portraits and monumental brasses. It should, however, be borne in mind that highly prepotent forms are capable from the first of so completely controlling the development that they transmit their peculiar traits to all their offspring.

\section{Is Ripeness of the Germ-Cells a Cause of Variation?}

While difference in age may sometimes account for the earlier broods and litters resembling (one of the parents, it fails to account for the very pronounced variation often found in a single brood or litter, and for much of the dissimilarity between members of the same human family. When a single fertilised germ-cell, as occasionally happens, gives rise to twins, they are always identical; hence it may be assumed the differences in members of the same family have their source in differences in the germ-cells from which they spring. If the offspring vary with the maturity of the soma, it may also vary with the maturity of the germ-cells, or at least with their condition at the moment of conjugation.

Some years ago Mr. H. M. Vernon, when hybridising echinoderms, discovered that "the characteristics of the hybrid offspring depend directly on the relative degrees of maturity of the sexual products" (Proceedings Royal Society, vol. Ixiii. May 1898). Mr. Vernon found subsequently that over-ripe (stale) ova fertilised with fresh sperms gave very different results from fresh ova fertilised with over-ripe (stale) sperms, from which he inferred that over-ripeness (staleness) is a very potent cause of variation (ibid., vol. lxv. November 1899).

I find that if a well-matured rabbit doe is prematurely (i.e., some time before ovulation is due) fertilised by a buck of a different strain, the young take after the sire; when the fertilisation takes place at the usual time, some of the young resemble the buck, some the doe, while some present new characters or reproduce more or less accurately one or more of the ancestors. When, however, the mating is delayed for about thirty hours beyond the normal time, all the young, as a rule, resemble the doe. It may hence be inferred that in mammals, as in echino. derms, the characters of the offspring are related to the condition of the germ-cells at the moment of conjugation, the NO. $166_{3}$, VOL. 64$]$ 
offspring resulting from the union of equally ripe germ-cells differing from the offspring developed from the conjugation of ripe and unripe germ-cells, and still more from the union of fresh and over-ripe germ-cells. This conclusion may be said to be in harmony with the view expressed by Darwin, that the causes which induce variability probably act "on the sex elements before impregnation has been effected " ("Animals and Plants," vol. ii. p. 259). The results already obtained, though far from answering the question why there is often great dissimilarity between members of the same family, may lead to further experiment, and especially to more complete records being kept by breeders. It is unnecessary to point out what a gain it would be were breeders able to regulate, even to a small extent, the characters of the offspring.

\section{Is the Condition of the Soma a Cause of Variation?}

There is a considerable amount of evidence in support of the view that changes in any part of the body or soma which affect the general welfare influence the germ-cells. This is but what might be expected if the soma in the metazoa is to the germcells what the immediate surroundings are to the protozoa. The soma from the first forms a convenient nidus for the germ-cells, and when sufficiently old and sufficiently nourished it provides the stimuli by which the ripening (maturing) of the germ-cells is effected. If in the case of the protozoa variation is due to the direct action of the environment, it may be inferred that in the metazoa variations of the germ-cells result from the direct action of the soma, i.e., from the direct action on the germ-cells of their immediate environment. This, however, is quite a different thing from saying that definite somatic variations are incorporated in the germ-cells (converted into germinal variations) and transmitted to the offspring.

It may first be asked, Does disease in as far as it reduces the general vigour or interferes with the nutrition of the germ-cells act as a cause of variation? I recently receired a number of blue-rock pigeons from India infected with a blood parasite (Halteridium) not unlike the organism now so generally associated with malaria. In some pigeons the parasites were very few in number, in others they were extremely numerous. The eggs of a pair of these Indian birds with numerous parasites in the blood proved infertile. Eggs from a hen with numerous parasites fertilised by a cock with a few parasites proved fertile, but the young died before ready to leave the nest. An old male Indian bird, however, with comparatively few parasites mated with a mature half-bred English turbit produced a single bird. The half-bred turbit has reddish iwings and shoulders, but is otherwise white. The young bird by the Indian blue-rock is of a reddish colour nearly all over, but in make not unlike the crossbred turbit hen.

Some time before the second pair of eggs were laid the parasites had completely disappeared from the Indian bird, and he looked as if he had quite recovered from his long journey, as well as from the fever. In due time a pair of young were hatched from the second eggs, and as they approached maturity it became more and more evident that they would eventually present all the distinctive points of the wild-rock pigeon. ${ }^{1}$ The striking difference between the first bird reared and the birds of the second nest might, however, be due not to the malaria parasites but to the change of habitat.

Against this view, however, is the fact that another Indian bird infected to about the same extent as the mate of the half bred red turbit counted for little when mated with a second half-bred turbit ; while two Indian birds in which extremely few parasites were found at once produced blue-rock-like birds when bred-one with a fantail, the other with a tumbler.

Another possible explanation of the difference between the bird of the first and the birds of the second nest is that the germ-cells were for a time infected by the minute protozoan Halteridium in very much the same way as the germ-cells of ticks are infected by the parasite of Texas fever. But of this there is no evidence, for even in the half-grown birds hatched by the pure-bred malarious Indian rocks the most careful exam ination failed to detect any parasites in the blood. In all probability Halteridium can only be conveyed from one pigeon to another by Culex or some other gnat.

These results with pigeons suffering from malaria seem to ndicate that the germ-cells are liable to be influenced by fevers

1 In these young birds the breast and some of the wing feathers are im. erfect. Fanciers regard this condition of the feathers as evidence of contitutional weakness.

$$
\text { NO. I663, vOL. 64] }
$$

and other forms of disease that for the time being diminish the vitality of the parents. Further experiments may show that the germ-cells are influenced in different ways by different diseases.

Sometimes the germ-cells suffer from the direct action of their immediate environment, from disturbance in or around the germ-glands. If, for example, inflammation by the ducts or other channels reaches the germ-glands, the vitality of the germcells may be considerably diminished; if serious or prolonged, the germ-cells may be as effectively sterilised as are the bacteria of milk by boiling.

In 1900 two mares produced foals to a bay Arab which had previously suffered from a somewhat serious illness involving the germ-glands. These foals in no way suggest their sire. This year I have three foals by the same Arab after he had quite recovered : one promises to be the image of his sire, and the other two are decidedly Arab-like both in make and action.

While the germ-cells are liable to suffer when the soma is the subject of disease, there is no evidence that they are capable of being so influenced that they transmit definite or particular modifications (unless directly infected with bacteria or other minute organisms); that, e.g., the germ-cells of gouty subjects necessarily give rise to gouty offspring. Doubtless if the germ cells, because of their unfavourable immediate surroundings, suffer in vigour or vitality, the offspring derived from them are likely to be less vigorous, and hence more likely than their immediate ancestors to suffer from gout and other diseases.

It would be an easy matter to give instances of the offspring varying with the condition or fitness of the parents; but it will suffice if, before discussing intercrossing, I refer to the influence of a change of habitat.

\section{is Change of Habitat a Cause of Variation?}

It has long been recognised that a change of surroundings may profoundly influence the reproductive system, in some cases increasing the fertility, in others leading to complete sterility. Exotic plants, sterile it may be at first, often become extremely fertile, and when thoroughly established give rise to new varieties. In the case of mares obtained from Iceland and the south of England sometimes a year elapses before they breed. An ArabKattiawar pony which arrived during April from India proved during the first three months quite sterile, owing, I believe, to loss of vigour on the part of the germ-cells, their vitality being only about one-tenth that of a home-bred hackney pony. But the fertility is apparently greatly impaired by even comparatively slight changes of environment. Lions which breed freely in Dublin seem to be sterile in London, and I heard recently that when bulls are changed from one district to another in the north of Ireland complete sterility is sometimes the result. The tendency of some exotic plants to "sport " after they become acclimatised is doubtless due to the fact that their new habitat is unusually favourable, their general vigour-so essential for new developments-is increased, and, probably because certain groups of germ units are constantly stimulated by the new food available, they give rise abruptly or gradually to new and it may be unexpected characters. No one doubts that the bodily vigour is liable to be impaired by fevers and other diseases, by changes in the habitat, unsuitable food, rapid and unseasonable changes of temperature, and the like ; hence it will not be surprising if further investigations prove that changes in the soma, beneficial as well as injurious, are reflected in the germ-cells, and thus indirectly induce variation. Moreover there are excellent reasons for believing that the germ-cells are influenced by seasonable changes, such as moulting in birds and changing the coat in mammals. In the case of pigeons, e.g., the young bred in early summer are, other things being equal, larger and more vigorous, and mature more rapidly, than birds hatched in the late summer or autumn. But however sensitive the germ-cells may be to the changes of their immediate environment, i.e., the soma or body in which they are lodged, there is no evidence whatever that (as Buffon asserted and Darwin thought possible) definite changes of the soma, due to the direct action of the environment, can be imprinted on the germ-cells. By the direct action of the environment-food, temperature, moisture, \&c. - the body in whole or in part may be dwarfed, increased, or otherwise modified; but such changes only influence the germ-cells in as far as they lead to modifications of the body as a whole. They may expedite or delay maturity, after the length of the reproductive period, interfere with the nutrition of the germ-cells, or retard the development of the embryo, but they seem incapable of giving rise to definite structural or functional variations in the offspring. 
Intercrossing and Interbreeding as Causes of Variation.

The belief was once common amongst naturalists that variability was wholly due to crossing, and at the present day naturalists and breeders alike agree that intercrossing is a potent cause of variability, and are unanimous in regarding interbreeding as an equally potent means of checking variability. The opinion is also general that intercrossing has a swamping influence; that having brought forth new forms it forthwith proceeds to destroy them. Darwin, when discussing reversion, points out that intercrossing often speedily leads to almost complete reversion to a long-lost ancestor, i.e., to the loss of recently acquired and the reappearance of long lost characters "Animals and Plants," vol. i. p. 22). When, however, he comes to deal with variability, he states that "crossing, like any other change in the conditions of life, seems to be an element, probably a potent one, in causing variability (ibid., vol. ii. p. 254), the offspring of the first generation being generally uniform, but those subsequently produced displaying an almost infinite diversity of character. As to the influence of inbreeding lie says, "close interbreeding, if not carried to an injurious extreme, far from causing variability, tends to fix the character of each breed (ibid., vol. ii. p. 25I).

These statements may be quoted in support of the very common belief that intercrossing is both a potent cause of variation and of reversion; that it produces new varieties one moment and swamps them the next. Whether intercrossing may be regarded as the immediate cause of variation or of reversion (it can hardly be both) depends on what is implied by variation. Obviously variation may be either progressive or retrogressive, i.e., the offspring may differ from their parents in having quite new characters or in presenting ancestral characters, or in being characterised by traits neither new nor old, due to new combinations of characters already recognised as belonging to the variety or species. When intercrossing results in the restoration of old characters, we have reversion or retrogressive variation; when to new combinations of already existing characters like new combinations in a kaleidoscope, we have new variations of a non-progressive kind, almost always characterised by more or less reversion; when, however, intercrossing results in the characters of one variety being engrafted on another, or to the appearance of characters quite new to the species, we have progressive variation. Judging from the results I have obtained, intercrossing of two distinct varieties results, as a rule, in the loss of the more striking characters of both parents, i.e. in more or less marked reversion, the extent of the loss generally depending on the difference between the forms crossed. For example, if an owl pigeon is crossed with a pigeon known among fanciers as an archangel, nondescript birds are obtained, which may at once, with a white fantail, give birds almost identical with a blue-rock-the common ancestor of all our breeds of pigeons. Intercrossing, on the other hand, rarely leads to the blending in one individual of the unaltered characters of two or more varieties, and it never results in the appearance of characters absolutely new to the species. In a word, the iminediate result of intercrossing distinct varieties is, as a rule, more or less marked reversion. But though intercrossing usually results in retrogressive variation, it is indirectly an extremely potent cause of progressive variation. This is due to the fact (better realised by botanists than zoologists) that cross-bred offspring (first crosses) are (unless the parents have been enfeebled by interbreeding) endowed with an unusual amount of vigour, i.e., intercrossing is of supreme importance, not only because it leads to the co-mingling of germ-plasms having different tendencies, but also and perhaps chiefly because of its rejuvenating influence. The importance of this rejuvenation is usually at once evident if intercrossing is immediately followed by interbreeding. The interbreeding of closely related forms generally reduces the vigour, and, as Darwin points out, "far from causing variability, tends to fix the character of each breed" ("Animals and Plants," vol. ii. p. 25I); but the intercrossing of first crosses (or of highly vigorous in dividuals closely related in either the direct or the collateral line) without appreciably weakening the constitution, often results in offspring displaying, to use Darwin's words, " an almost infinite diversity of character" (ibid., vol. ii. p. 256). The epidemics of variation, so often the outcome of interbreeding first or at least vigorous recently produced crosses, are apparently partly due to the union of individuals having a similar tendency checking reversion, and partly to the vigour acquired by recent NO. I663, VOL. 64] intercrossing. This much may be inferred from the fact, that when interbreeding is persisted in the variability dwindles as the vigour ebbs.

Breeders agree with Darwin that first crosses are generally uniform, and that the subsequent offspring usually vary immensely; yet neither breeders nor naturalists seem to have clearly realised that interbreeding at the right moment is the direct cause of variation, while intercrossing is, except in very rare cases, at the most an indirect. cause of variation.

It may be here said that it is impossible to over-estimate the importance of vigour in studying variation. Without vigour no race or breed can maintain its position; without renewed vigour it is hardly likely to develop new characters. The new vigour, as already explained, may be cbtained by intercrossing ; but it may also be acquired, especially in plants, by a change of surroundings accompanied by a plentiful supply of suitable food.

With rigid selection the gradual loss of vigour may escape notice, but when selection is suspended rapid deterioration (from the fancier's standpoint) is the inevitable result. If, e.g., a number of pigeons, good specimens of a distinct breed, are isolated and left unmolested for a few years, they rapidly degenerate, i.e., they lose their show points (be they peaks, frills, ruffs, or metallic tints) and reassume the more fixed ancestral characters. If, however, the less characteristic birds are eliminated, and high-class birds are from time to time introduced from another loft, the vigour and the distinctive traits are indefinitely preserved.

If the age and condition of the soma and the state of ripeness of the germ-cells are potent factors, and especially if vigour counts for much, the difficulties of breeders become intelligible, and the unlikeliness of intercrossing being a direct cause of variation all the more evident. The most that can be expected from intercrossing is the engrafting on one breed the characters of another. Even this rarely happens, and is only possible when the two breeds are somewhat allied. It is impossible, e.o., to unite in one individual all the points of a fantail and a pouter, or of a fantail and a jacobin; but given healthy, vigorous birds, the points of an owl may be engrafted on a barb. Or to take another example, the black ears, feet, \&c., of a Himalaya rabbit may be combined with the characteristic form, long hair and habits of an Angora. It may be impossible to predict what will happen when intercrossing is resorted to, but if pure-bred members of a distinct variety are experimented with -and it is useless working with either plants or animals of un. known origin-characters not already present in one of the varieties need not be looked for.

But while interbreeding at the right moment may be a cause of progressive variation, at other times it leads to what is perhaps best described as degeneration. When, e.g., very young members of the same brood or litter, or unhealthy, closely related individuals, or quite mature and apparently vigorous but for several generations closely related animals are interbred, the offspring frequently differ from their parents. They are often delicate and highly sensitive, and unable to survive unless provided with highly nutritious food; and though they mature numerous germ-cells they rear but few offspring, and, what is still more striking, they are sometimes either white or all but devoid of pigment. Offspring thus characterised, especially when white or nearly white in colour, e.g., nearly white pheasants, partridges, and woodcock, white specimens of the brown hare, white squirrels, \&c., are sometimes regarded as distinct varieties, but when the departure from the normal colour, \&c., is the result of close inbreeding it is best regarded as degeneration.

In the spring of I 900 I crossed a quarter-wild grey doe rabbit with a closely inbred black-and-white buck. The young obtained varied considerably in colour : to one of her offspring coloured like the sire, the grey doe produced a second litter, all but one decidedly lighter in colour than the sire. Two of the darker members of this litter produced almost white young, and to one of them the original grey doe has recently produced a light-coloured litter consisting of two pure white specimens, two with only a narrow dorsal band, two fawn-coloured and one black. Close interbreeding with goats and pigeons yields similar results. Birds on small remote Pacific islands are sometimes marked with irregularly disposed white patches. These pie-bald birds, like light-coloured pheasants, cream-coloured partridges and dun-coloured rooks, may also be the victims of close inbreeding. 
The Swamping Effects of Intercrossing.

The question "Are new varieties liable to be swamped by intercrossing?" is perhaps the most important now pressing for an answer from biologists. What would happen, for example, if specimens of all the different breeds of cattle were set free and left unmolested on a large area? Would they some centuries hence be represented by several breeds or by one? Many would answer this question by saying that unless some of them in course of time were isolated by mountains, deserts, or other physical barriers, they would eventually through intercrossing give rise to a single breed. To this question Darwin would, I think, have given a somewhat different answer, for, while, admitting " that isolation is of considerable importance in the production of new species," he was, on the whole, "inclined to believe that largeness of area is of more importance ("Origin of Species," p. 104). Unfortunately Darwin nowhere indicates how he supposed new varieties escape being swamped by intercrossing. His silence on this important point is difficult to explain, for during his lifetime the influence of intercrossing in checking progress except in one direction was often enough insisted on. Huxley tells us that in his earliest criticisms of the "Origin" " he ventured to point out that its logical foundation was insecure so long as experiments in selective breeding had not produced varieties which were more or less infertile" ("Life of Professor Huxley," p. I70). Later Moritz Wagner and others pointed out the important part physical isolation had played in the origin of species; and later still Romanes endeavoured to show how the blighting influence of free intercrossing might be overcome by physiological selection, Romanes, like Huxley, believing several varieties might be evolved in the same area if more or less mutually infertile. Evidence of the importance of physical isolation is plentiful enough; but neither has experimental nor selective breeding proved that physiological isolation has been instrumental in arresting the swamping effects of intercrossing. Hence, according to Huxley and others, the foundation of Darwin's doctrine of natural selection must still be regarded as insecure. Is intersterility the only possible means by which new varieties can be saved from premature extinction, from being destroyed before they have a chance of proving their fitness to survive? In other words, are barriers as essential among wild as among domestic animals? It does not seem to have occurred to the biologists who so fully realised the need of isolation that the old varieties instead of swamping might be swamped by the new, and that several varieties might sometimes be sufficiently exclusive to flourish and eventually give rise to a like number of species in the same area. If on an island two new varieties of sheep appeared sufficiently vigorous, or, as we say, sufficiently prepotent, to swamp all the other varieties-as the ill-favoured lean kine did eat up the fat ones-and yet so exclusive that their cross-bred offspring invariably belonged to the one new variety or the other, for their preservation fences and other barriers would be superfluous.

Is there any evidence that by prepotency the swamping of new varieties is sometimes checked, and that by exclusive inheritance two or more varieties, though mutually fertile, may persist in the same area, occasionally intercrossing with each other, but neither giving up nor taking from each other any of their distinctive characters? I have in my possession a skewbald Iceland pony that produces richly striped hybrids to a zebra, but skewbald offspring the image of herself in make, colour, and temperament to whole-coloured bay Arab and Shetland ponies. This pony instead of being swamped invariably swamps older breeds. A number of prepotent skewbald ponies, wherever placed, would (especially with the help of preferential mating) in all probability soon give rise to a distinct race such as once existed in the East. What is true of the Equidæ is equally true of other groups. Black hornless Galloway bulls are often so prepotent that their offspring with long-horned brightly-coloured Highland heifers readily pass for pure-bred Galloways. The wolf is so prepotent over the dog, as the wild rabbit, rat, and mouse are prepotent over their tame relatives. As an instance of prepotency in rabbits, I may give the results of an interbreeding experiment with a grey doe, the granddaughter of a wild rabbit, and an inbred buck richly spotted like a Dalmatian hound. Of six young in the first litter three were like the sire. To one of her sons, the grey doe next produced eight young, all richly spotted, and subsequently to one of her spotted grandsons she produced two spotted, two white, and two grey offspring. Similar results are obtained with plants ; hybrid orchids, e.g., sometimes reproduce all the characters of one of the parents.

It need hardly be insisted on that if new varieties, well adapted for therr environment, are not only sufficiently prepotent to escape being swamped by other varieties, but are also, like the spotted rabbit, able to hand on the prepotency almost unimpaired to a majority of their descendants, progressive development along a definite line will be possible. But of even more importance than prepotency is what for want of a better name may be known as exclusive inheritance. Recently a vigorous mature Indian blue-rock pigeon mated with an inbred and equally mature fantail, hatched and reared two birds, one exactly like a blue-rock, but with fourteen instead of twelve tail feathers; the other characterised by all the points of a highclass fantail, the tail feathers being thirty in number-two fewer than in the fantail parent, but eighteen more than in the bluerock parent. In this case the blue-rock was the exclusive bird, the fantail having previously produced birds with only sixteen feathers in the tail when mated with an ordinary dovecot pigeon. A still more striking example of exclusive inheritance we have in the crow family. The carrion crow and the hooded crow are so unlike in colour that they were long regarded as two distinct species; now they are said to be two varieties of the same species. The carrion crow is black all over, but in the hooded crow the breast and back are grey. These two crows cross freely (but for this they would probably still rank as distinct species); but in the crossbred young there is never any blending - they are either black or grey, usually both varieties occurring in the same nest. Similar exclusiveness occurs amongst mammals. When distinct varieties of cats are crossed, some of the young usually resemble one breed, some the other, and the distinctions may persist for several generations. A white crossed with a tabby-coloured Persian cat produced a pair of white and a pair of tabby-coloured young ; the two white cats when interbred also produced two white and two tabbycoloured individuals. I find cats are far more exclusive than rabbits ; perhaps it is partly for this reason we have so many species and varieties of wild cats, so few species and varieties of wild rabbits. Another very striking instance of exclusiveness we have in the Ancon or "Otter" sheep common in New England at the end of the eighteenth century. This breed, which was characterised by short crooked legs and a long back like a turnspit dog, descended from a ram-lamb born in Massachusetts in $x 791$. The offspring of this "sport" were never intermediate in their characters ; they were either like the original Ancon ram or like the breeds, some thirteen in number, with which he was mated. Frequently in the case of twins one was otter-like, the other an ordinary lamb. More remarkable still, the Ancon-like crosses, generation after generation, were as exclusive as their crooked. legged ancestor.

Another familiar example of exclusiveness we have in the peppered moth, a dark variety of which in a few years swamped the older light variety throughout a considerable part of England, and is now extending its range on the Continent. It thus appears that when a new variety is sufficiently prepotent, instead of being swamped it may actually swamp the old-established variety; and that when two or more varieties are sufficiently exclusive they may flourish side by side, and eventually give rise to two or more distinct species.

Prepotency may hence be said to supplement and complete the work of the environment. The environment seems to be mainly concerned in eliminating the unfit; whether any of the survivors persist depends not so much on their surroundings as on whether they are sufficiently prepotent and exclusive to escape being swamped by intercrossing. This way of accounting for progress in one or more directions may prove as inadequate as the one suggested by isolationists, but it has the merit of being more easily tested by experiment. It not only gets rid of the swamping bugbear, but makes it matter of indifference whether (to quote from the President's address at the last Oxford meeting of the Association) " the advantageously varied bridegroom at the one end of the wood meets the bride, who, by a happy contingency, had been advantageously varied in the same direction, and at the same time, at the other end of the wood." Further, as a highly prepotent vigorous variety can well afford to maintain a number of budding organs, it helps us to understand how luminous, electric, and certain other structures were nursed up to the point when they began to count in the struggle for existence. NO. I663, VOL. 64] 


\section{Doubtful Causes of Variation.}

Having indicated how maturity of the soma and of the germcells, and how bodily welfare and interbreeding may act as causes of variation, and also how swamping of the new variations may be checked, I shall now refer to certain supposed causes of variation.

\section{Maternal Impressions.}

I may begin with the widespread belief that the offspring are capable of being influenced in form, colour, and temperament by maternal impressions-the belief we associate with the skilful shepherd who peeled wands and stuck them up before the fulsome ewes. Muller ("Elements of Physiology," vol. ii. p. 1405) more than half a century ago, conclusively argued against the belief in maternal impressions, but the belief still prevails. I know of two able naturalists who subscribe to the maternal impression doctrine, and it is firmly held by many breeders and by not a few physicians. A writer in a recent number of a quarterly (Bibby's Quarterly, Autumn Number, 1900, p. 163), which circulates widely amongst farmers and stock-keepers, boldly asserts that the existence of impressions which affect progeny (more especially in colour) is a settled fact. This writer supports his case by referring to a highly successful breeder of polled Angus cattle, who considered it necessary to surround his herd " with a tight black fence in order to keep the females from dropping red calves because they saw the red herds of his neighbours." Reference is also made by this writer to the belief, common in certain parts of England, that whitewashed byres, regardless of the colour of the parents, produce lightcoloured calves; that the colour of foals is often more influenced by the stable companion of the dam than by her own colour or that of the sire; and that even the colour of birds varies with the immediate surroundings, fowls, e.g., however carefully penned, hatching birds resembling in colour the hens they habitually see in a neighbouring run. If maternal impressions thus influence the offspring they must be one of the most effective causes of variation. During the last six years I have bred many hundreds of animals, but the nearest approach to an instance of maternal impressions was a dark pup with a white ring half round the neck, which suggested the white metal collar sometimes worn by his sire. But similar rings round the legs and tail rather discredited the view that the white neck-ring was in any way related to the sire's nickel-plated collar. Telegony was sometimes said to be due to maternal impressions. It was doubtless for this reason that I was urged some years ago to carefully prevent the mares used in my experiments from seeing too much of the zebras. But though numerous foals have been bred from mares stabled with zebras or grazing with richly striped zebra hybrids, not a particle of evidence have I found in support of the maternal impression doctrine. The foals have neither stripes nor uprigh manes, and do not even attempt to mock the weird barking call of the zebra. Sheep and cattle, goats, rabbits and guinea-pigs, fowls and pigeons, have simply confirmed the results obtained with horses. This being the case, grooms may very well omit following the practice (considered so essential in Spain during the Middle Ages, and still often religiously observed in England and America) of setting " before the mares . . . the most goodly beasts" by way of hinting to them the kind of foals they are expected to produce.

\section{The Needs of the Organism as a Cause of Variation.}

No recent biologists are perhaps prepared to believe like Lamarck that the wings of birds were developed by their remote ancestors making efforts to fly; that by stretching its toes the otter acquired webbed feet ; nor are they prepared to find in our new mammal, the Ocapi, evidence in support of Lamarck's contention that to meet new needs the giraffe by much stretching gradually lengthened his neck. Yet it is difficult sometimes to see any real difference between the beliefs of the new Lamarckians and the old. It is maintained, for example, "that when a certain functional activity produces a certain change in one generation it will produce it more easily the next," that, e.g., flounders and their allies by constant efforts generation after generation have dragged the left eye to the right side, while by similar efforts in the turbot and certain other flat fishes the right eye has been shifted to the left side. It is not alleged by NeoLamarckians that globe fishes resulted from round fishes blowing themselves out, or that flounders resulted from round fishes generation after generation making efforts to flatten themselves. NO. I $66_{3}$, VOL. 64$]$
If by germinal variation and selection flounders were evolved out of round fishes, is it not straining at a gnat and swallowing a camel to refuse to admit that by the same factors the left eye of the flounder has been transferred from the left to the right side of the head? In the flat fishes it is not difficult to imagine how by variation and selection the eyes originally acquired the power of responding to certain external stimuli.

\section{The Direct Action of the Environment and Use-Inheritance as Causes of Variation.}

Of the doctrine of the transmission of acquired characters, still so often the subject of discussion, I need say little more than that I have failed to discover any evidence in its favour. Writing in 1876 , Darwin says, "In my opinion the greatest error which I have committed has been not allowing sufficient weight to the direct action of the environment, i.e., food, climate, \&c., independently of natural selection" "Life and Letters": Letter to Moritz Wagner). Darwin not only in his later years reverted to the teaching of Buffon, but in as far as be continued to believe in the "inherited effects of use and disuse" he adopted the views of Erasmus Darwin and Lamarck. While admitting that the direct action of the environment on the soma and use-inheritance are indirect-it may be potent--causes of variation, I do not believe there is any trustworthy evidence in support of the view that definite somatic variations are ever transmitted.

\section{Telegony as a Cause of Variation.}

The belief in telegony is less deserving of consideration than the doctrine of the transmission of acquired characters. Never theless I perhaps ought to refer to it at greater length, not so much because of its scientific importance, but because it interests all sorts and conditions of men in many different parts of the world. Telegony ("infection of the germ" of older writers) means that not only the immediate parents but also the previous mates (if any) contribute to the characters of the offspring; that e.g., a mare which had produced foals to, say, "Ladas" and "Persimmon" might thereafter give birth to a foal by "Flying Fox," to which "Ladas" and "Persimmon," as well as the actual sire, contributed some of their characteristics. Many even think a sire may transmit definite structural characters from one mate to another. If there is such a thing as telegony, if it is possible to blend without the risks of intercrossing the characteristics of several individuals or varieties, progressive development would be greatly accelerated. Though the doctrine of "infection" has probably long formed part of the breeder's creed, it received but little attention from men of science until in 1820 Lord Morton communicated a case of infection to the Royal Society, which in due time was published in the Philosophical Transactions. In this the most credible and best authenticated of all the cases of telegony on record a chestnut mare, after rearing a quagga hybrid, produced to a black Arabian horse three foals of a peculiar bay colour, one of them (a filly) showing more stripes than the quagga hybrid, and, according to the stud groom in charge of "the colts," characterised by a mane "which from the first was short, stiff, and upright" (Phil. Trans., 1820, p. 21). Darwin, after fully considering Lord Morton's case, came to the conclusion that the chestnut mare had been infected, and this case along with others led him to believe that the first male influenced "the progeny subsequently borne by the mother to other males" ("Animals and Plants," vol. ii, pp. 435 436.) If the upright zebra-like mane in one of the pure-bred colts and the markings on all three were the result of the chestnut mare having been first mated with a quagga, there is undoubtedly such a thing as telegony, and the presumption is that other mares first mated with a quagga or zebra and then with a black Arabian would give birth to striped offspring with a stiff if not quite upright mane. The evidence that from the first the mane of the filly was short, stiff, and upright is most unsacisfactory. It consists of an allegation by a stud groom. That the mane was upright, as in the quagga and zebra, is a priori improbable (I) because the mane of the quagga hybrid instead of being short and stiff was long and lank enough to arch to one side of the neck; $(2)$ because the mane of zebra hybrids throughout the greater part of the year is so long that it falls to one or it may be both sides of the neck; and (3) because in the Equidæ an upright mane is always accompanied by a tail deficient of hairs at the root-in the filly the tail is as perfect as that of her Arab sire. We have still stronger evidence that the allega. tion of the groom was unfounded from drawings (of the chestnut mare, her three "colts," the black Arab, the quagga, and the 
quagga hybrid) by Agasse, a very trustworthy animal painter of the early part of last century. In the drawing of the filly the mane is represented as lying to one side, as in Arabs and other wellbred horses. The pictures (now in the Museum of the Royal College of Surgeons, London) were made because the subsequent foals were believed to prove the truth of the "infection" doctrine. Had the mane of the filly been erect it would hardly have escaped the keen eyes of the artist. But had Agasse by any chance missed this all-important detail, Lord Morton or some of those interested would doubtless have called his attention to the matter. If the mane of an Arab is completely removed early in the spring it is stiff, and upright in the autumn, but hanging to one side close to the neck in the following summer. When the whole circumstances are taken into consideration, there seems to me no escape from the conclusion that the mane of the filly was upright when seen by Lord Morton in August, 1820 , and lying to one side when painted by Agasse the following summer, because it had been regularly cropped or at least hogged some months before Lord Morton's visit. But whatever be the explanation of the want of agreement between the mane as seen by Lord Morton and as depicted by Agasse, it will, I think, be admitted that the evidence afforded by the mane of the filly is hardly sufficient to establish the truth of the doctrine of telegony. Of still less value is the evidence afforded by the make, coat, colour and markings which were apparently too indistinct to deserve the name of stripes. The colts were decidedly Arab-like, of a bay colour marked more or less " in a darker tint." Judging from Agasse's drawings they closely resemble Arab-Indian crosses; they are, in fact, in make very like the Arab-Kattiawar horse already referred to. I have seen a bay Highland cob with as many stripes as Lord Morton's colts, and pure-bred Arabs of a dun colour with stripes on the neck and far more distinct leg bars than those depicted by Agasse. I believe the colts owed their stripes and colour not to "infection" of their dam by her previous mate the quagga, but to reversion. It is quite possible the black Arabian horse was of mixed origin; that the chestnut mare was crossbred is admitted. As in the west of Ireland the offspring of black and chestnut ponies are sometimes of a decidedly dun colour, it is not surprising that the black Arab and the half-bred chestnut had bay offspring. Neither are the stripes surprising. I recently ascertained that the chestnut mare was presented to Lord Morton (while serving with his regiment in India) by one of his officers-Mr. Boswell, of Deeside, Aberdeenshire-and that she was most likely a cross between an Arab and a country-bred pony. In Kattiawar the ponies when pure-bred are of a rufous grey colour and more or less richly striped. If in the chestnut mare there was any Kattiawar or even any native pony blood its offspring to a black sire might have been expected to be of a dun colour and striped. In a word, there is no reason for assuming that the foals would have been less striped if the chestnut mare had been mated with the black Arab first and the quagga afterwards.

By way of testing the truth of the "infection" doctrine I started, in 1895 , a number of experiments, and especially arranged to repeat as accurately as possible, what is commonly called Lord Morton's experiment. Since then twelve mares after producing sixteen zebra hybrids, a mule, and a hinny have had an opportunity of supporting the telegony hypothesis by giving birth to twenty-two pure-bred foals.

During the same period Baron de Parana of Brazil has bred at least six zebra hybrids, and some of the dams of these hybrids subsequently produced ordinary foals. Further, Baron de Parana has for a number of years been engaged in crossing cattle and in watching the results obtained in several mulebreeding establishments, where from 400 to 1000 brood mares are kept. As in these establishments the mares breed mules and horses alternately-two or three mules and then a horse foal-there has been carried on for some years, under the observation of Baron de Parana, a telegony experiment on a gigantic scale.

The single hybrid bred by Lord Morton had extremely few stripes, and only in a remote way suggested a member of the zebra family. All my hybrids, like those bred in Brazil, have more stripes than their zebra sire, and in some of them the bands are nearly as conspicuous as in some of the zebras, thus proving that both the mares (which varied in colour and breed) and the two zebra stallions used were well adapted for the experiment. The results of my experiments, not only with the Equidæ but also with other domestic quadrupeds and birds, all point to the conclusion that there is no such thing as telegony, and the same conclusion has been independently arrived at by Baron de Parana in Brazil. Believers in telegony-they are numerous in America, India, and Australasia, as well as in Eng. land-almost always say of the many experiments recently made with a view to giving "infection" a chance of showing itself that they have only yielded negative results, and they generally add, it is impossible to prove a negative. After carefully considering all the more striking so-called cases of "infection," I have no hesitation in saying that there is no satisfactory evidence that there has ever been, either in the human family or amongst domestic animals, a single instance of infection.

I have in a hurried and imperfect manner indicated that we are not likely to find either in maternal impressions, the direct action of the environment, use-inheritance, or telegony a true cause of variation. I have endeavoured to point out that, instead of simply stating that variation is due to the constant recurrence of slight inequalities of nutrition of the germ.cells, we may with some confidence assert that differences in the age, vigour, and health of the parents and differences in the ripeness of the germ-cells are potent causes of variation.

I have also endeavoured to prove that intercrossing, though a direct cause of retrogressive variation, is only an indirect cause of progressive variation, while interbreeding (in-and-in breeding) at the right moment is a cause of progressive variation.

Further, I have discussed at some length the swamping effects of intercrossing, chiefly with the object of showing (I) that progress in a single direction is probably often due to new varieties swamping old, it may be long established, varieties; and (2) that several varieties may be sufficiently exclusive to flourish side by side in the same area, and eventually (partly owing to their aloofness, i.e., to differential mating) give rise to several new species.

I have only now to add that I was mainly led to select "The Experimental Study of Variation" as the subject of my address that I might indirectly indicate that the time had come when a well-equipped institute should be provided for biological and other experiments.

\section{NOTES.}

THE Times announces that the Indian Government have adopted the suggestion of the Royal Society for the carrying out of a magnetic survey. The existing magnetic observatories at Bombay and Calcutta being inadequate as base stations for the vast area the survey will cover, similar observatories are in course of construction at Dehra Dun, at Kodaikanal, and at Rangoon. The Dehra Dun observatory will be under the supervision of Colonel Grore, R.E., the Surveyor-General of the Indian Survey (whose headquarters are located there); but the other four will be in charge of Mr. John Eliot, the meteorological reporter to the Government. The Survey and Meteorological Departments will, in fact, be jointly responsible for the investigations. The field observations will be carried out by six or seven detachments of the Survey Department, and these will be controlled by Captain Fraser, R.E., who has recently been arranging in England for the purchase of the necessary instruments. Sind and the Punjab will first be taken in hand; and, as the country is now intersected with railways in all directions, enabling field detachments to quickly cover the distances from one observing station to another, it is anticipated that five years will suffice to complete the field work of the preliminary magnetic survey.

IT is stated that a committee is being formed at Amalfi to arrange for the celebration of the fourth centenary of the invention of the compass. The Duke of the Abruzzi has agreed to be president of the committee; and Signor Morin, the Minister of Marine, the vice-president. The celebration will take place next year.

To obtain information for the Lightning Research Committee organised by the Royal Institute of British Architects and the Surveyors' Institution, the Institution of Electrical Engineers has

$$
\text { NO. I663, VOL. } 64]
$$

